\title{
CYFRA 21-1 and MMP-9 as salivary biomarkers for the detection of oral squamous cell carcinoma: a systematic review of diagnostic test accuracy
}

Dol:

10.1016/j.ijom.2020.01.020

\section{Document Version \\ Accepted author manuscript}

Link to publication record in Manchester Research Explorer

Citation for published version (APA):

Alali, A. M., Walsh, T., \& Maranzano, M. (2020). CYFRA 21-1 and MMP-9 as salivary biomarkers for the detection of oral squamous cell carcinoma: a systematic review of diagnostic test accuracy. International Journal of Oral and Maxillofacial Surgery. https://doi.org/10.1016/j.ijom.2020.01.020

\section{Published in:}

International Journal of Oral and Maxillofacial Surgery

\section{Citing this paper}

Please note that where the full-text provided on Manchester Research Explorer is the Author Accepted Manuscript or Proof version this may differ from the final Published version. If citing, it is advised that you check and use the publisher's definitive version.

\section{General rights}

Copyright and moral rights for the publications made accessible in the Research Explorer are retained by the authors and/or other copyright owners and it is a condition of accessing publications that users recognise and abide by the legal requirements associated with these rights.

\section{Takedown policy}

If you believe that this document breaches copyright please refer to the University of Manchester's Takedown Procedures [http://man.ac.uk/04Y6Bo] or contact uml.scholarlycommunications@manchester.ac.uk providing relevant details, so we can investigate your claim.

\section{OPEN ACCESS}


2 Title: CYFRA 21-1 and MMP-9 as Salivary Biomarkers for The Detection of Oral Squamous Cell

3 Carcinoma (OSCC): A Systematic Review of Diagnostic Test Accuracy

4

5 Authors:

6

1. Ahmad M. AlAli ${ }^{1,3}$

7 alali.a@hotmail.com

8

2. Tanya Walsh ${ }^{1}$

9 tanya.walsh@manchester.ac.uk

3. Massimo Maranzano ${ }^{2}$ massimo.maranzano@manchester.ac.uk

$12{ }^{1}$ Division of Dentistry, School of Medical Sciences, Faculty of Biology, Medicine and Health,

13 The University of Manchester, Manchester, United Kingdom

$14{ }^{2}$ Oral and Maxillo-Facial \& Facial Plastic Surgery Department, Manchester University NHS

15 Foundation Trust, Manchester, United Kingdom

$16{ }^{3}$ Oral and Maxillofacial Department, Al-Adan Specialised Dental Center, Ministry of Health, Kuwait 17

18 Corresponding author:

19 Ahmad M. AlAli,

20 Division of Dentistry, School of Medical Sciences, Coupland 3 Building, The University of

21 Manchester, Manchester, United Kingdom, M13 9PL.

22 +965-97972742 / Alali.a@hotmail.com

24 Key words:

25 Oral cancer, oral squamous cell carcinoma, OSCC, salivary biomarkers, CYFRA 21-1, MMP-9 
Abstract

27 Tissue biopsy with histopathological examination is still considered as the gold standard to

28 diagnose oral-squamous-cell-carcinoma (OSCC). This systematic review explores the diagnostic test accuracy of two salivary biomarkers in adults suspected of OSCC.

30

Cochrane Library, MEDLINE and EMBASE were searched for clinical studies evaluating the diagnostic accuracy of salivary biomarkers in detecting OSCC. Studies were eligible for inclusion if only singular salivary biomarkers were evaluated in three or more studies. Studies investigating combined salivary biomarkers or assessing patients with oral-potentiallymalignant-disorders only were excluded. The reporting of the review follows the PRISMA checklist.

Six studies, recruiting 775 participants, were included in this review for only two salivary biomarkers, CYFRA 21-1 and MMP-9. The sensitivity and specificity values (with 95\% $\mathrm{Cl}$ ) for CYFRA 21-1studies ranged from $0.84(0.75-0.91)$ to $0.94(0.83-0.99)$ and $0.84(0.71-0.93)$ to $0.96(0.80-1.00)$ respectively. While in MMP-9 studies, the sensitivity values (with $95 \% \mathrm{Cl}$ ) ranged from $0.76(0.67-0.83)$ to $1.00(0.78-1.00)$ and specificity values from $0.27(0.12-0.46)$ to $1.00(0.78-1.00)$. The overall quality of the included studies was poor.

Due to a lack of strong and high-quality of evidence, considerable uncertainty remains surrounding the use of singular salivary biomarkers for the detection of OSCC. 


\section{INTRODUCTION}

49

50 Many different techniques and tests delivered in a variety of settings are available for the

detection of oral squamous cell carcinoma (OSCC). Conventional oral examination (COE)

52 carried out by a general dental practitioner has traditionally been recommended by various health and medical/dental organisations as a part of oral cancer $(\mathrm{OC})$ screening programs e.g. BDA.(1) A Cochrane systematic review has evaluated the diagnostic accuracy of a variety of tests as adjunct tests to the COE in a dental setting including vital staining, oral cytology, lightbased detection or oral spectroscopy in patients presenting with clinically evident lesions.(2)

Their findings showed that cytology tests appeared to have the greatest potential, and warranted further investigation. However, the overall quality of the evidence was variable, with insufficient evidence to justify the replacement of the current 'gold standard' diagnostic test of scalpel biopsy with histopathological examination in addition to the COE.

61

Comparatively, saliva, also known as the "mirror of the body", is an easy medium to be collected for bioanalysis. Sample/specimen collection is non-invasive, inexpensive and simple, which makes it ideal method for diagnostic purposes.(3) Saliva contains an extensive number of compounds, is safe to handle and store, does not clot, and as such, it is deemed a promising diagnostic biofluid. (4) Two systematic reviews have evaluated the performance of a wide range of salivary biomarker expression in OSCC. $(5,6)$ However, these systematic reviews mainly included 'case-control' type accuracy studies, which can be prone to bias. Studies which compare altered expression of a specific salivary biomarker in 'cases' with OSCC with those in healthy 'control' participants can deliver misleading results when the methods of participant recruitment are not taken into consideration (7). If participants representing only 
72 subgroups of the spectrum of disease and spectrum of non-diseased are included, the

73 resulting estimates of diagnostic test accuracy may not be applicable to the clinical question.

74 (8)

75

76 OSCC is an increasing disease globally. Several factors have been implicated in the

77 development of the disease such as tobacco, betel quid, alcohol, and others like human

78 papillomavirus (HPV) and Epstein-Barr virus (EBV). The survival rate of individuals with OSCC

79 is approximately $90 \%$ when detected early, compared to only $50 \%$ after delayed diagnosis.(9)

80 Hence, both prevention and early detection of disease are crucial in reducing OSCC mortality.

81

82 This systematic review aims to identify and summarise the diagnostic accuracy of salivary

83 biomarkers currently being used in the detection of OSCC in adults. The reporting of the

84 review follows the PRISMA checklist.(10)

85

86 


\section{MATERIALS AND METHODS}

88

89

90

91

92

93

94

95

96

97

\subsection{Study Criteria}

Studies were eligible for inclusion in the review if they were evaluating salivary biomarkers that reported measures of diagnostic test accuracy such as sensitivity and specificity in detecting OSCC; in adults (aged 16 years or over) suspected of having OSCC with no prior treatment such as chemotherapy or radiotherapy.

\subsubsection{Inclusion and Exclusion Criteria}

Only studies evaluating the performance of singular salivary biomarkers (index test) against any type of tissue biopsy with histopathological examination (reference standard) for the diagnosis of OSCC were eligible for inclusion. Studies were eligible for inclusion in the review if only singular salivary biomarkers were evaluated and where the performance of a salivary biomarker was assessed in three or more studies. Studies investigating combined salivary biomarkers or assessing patients with oral potentially malignant disorders (PMDs) only were excluded.

\subsection{Search Protocol and Study Selection}

An electronic search was performed on 14 June 2018 for studies published within the last five years (from 2014 to 2018) using the following databases: Cochrane Library, MEDLINE via OVID, and EMBASE via OVID. The search strategy used: (oral cancer OR mouth cancer OR oral squamous cell carcinoma OR OSCC).mp AND (diagnos* OR detect*).mp AND (saliva* AND (marker* OR biomarker* OR test)).mp. Following the removal of duplicates, the titles or/and abstracts of the retrieved records were screened for relevancy, and full-text articles were 
111 included following consensus among all three authors.

\subsection{Data Extraction}

114 The following data were extracted from each included study: (1) Study information and setting

115 (country, design, sample size, test used), (2) Type of salivary biomarker, (3) Study results: true positive (sensitivity) and true negative (specificity), and positive and negative predictive values

117 where reported; a $2 \times 2$ table was constructed for each study (reference standard against the

118 index test) using Review Manager 5.3.(11) The corresponding author of a study was contacted

119 via e-mail where further information or explanation was needed.

120

\subsection{Assessment of Methodological Quality}

122 By using a tailored QUADAS-2 tool, the quality of the included studies (risk of bias and applicability concerns) was assessed through its 4 domains: patient selection, index test, reference standard and flow and timing of participants through the study.(12) The indicators of the assessment of quality (QUADAS-2) are summarized in Table 1 as adapted from Macey et al.(2) The results then were graphically presented using RevMan.(11)

\subsection{Statistical Analysis and Data Synthesis}

129 The target condition (disease positive) was OSCC. The true positive, true negative, false 130 positive and false negative values were used to construct $2 \times 2$ tables for each study.(12) The

131 diagnostic test accuracy results of each biomarker were expressed as sensitivity and specificity with 95\% confidence intervals. Results were presented graphically as coupled forest plot for each salivary biomarker. 


\section{RESULTS}

Following the removal of duplicates, the electronic search yielded a total of 250 records, of which 224 were excluded, and 26 were further assessed for eligibility (Appendix 1). Only 6 studies met the inclusion criteria in this review as illustrated in the PRISMA flow-diagram in Figure 1. (10) The main reason for exclusion was the low number of studies that investigated each salivary biomarker (Appendix 2). Only if a biomarker had 3 or more studies was it eligible to be included in the review. Thus, only six studies reported the diagnostic accuracy of salivary biomarkers CYFRA 21-1 (13-15) and MMP-9 (16-18) in detecting OSCC were included.

\subsection{Description of Studies}

The included studies evaluated data from a total of 775 patients (355 patients for CYFRA 21-1 and 420 patients for MMP-9). From the total number, 356 (46\%) patients were diagnosed with OSCC according to the reference standard of biopsy and histopathological examination (180 (54\%) patients for the CYFRA 21-1 studies and 176 (42\%) patients for MMP-9), while the remaining 419 patients were classed as disease free or non-OSCC (175 patients for CYFRA 21-1 and 244 patients for MMP-9). The three CYFRA 21-1 studies were of Indian origin (13-15), while the three MMP-9 studies were from Egypt (16), Germany (17), and Taiwan (18). Salivary sample collection was carried out in a hospital setting (academic or dental/medical centres) between 2008 and 2014.

Classification and reporting of OSCC varied across studies, making meta-analysis inappropriate; two studies reported OSCC stages only (I to IV) $(16,18)$; one study reported OSCC grades only ( 1 and 2) (14); two studies reported both OSCC stages (0 through IVA) with 
grades ( 1 to 3$)(13,15)$; one study reported OSCC grades ( 1 to 4$)$ but reported stages in TNM system separately. (17)

159

\subsection{Methodological Quality of Included Studies}

161 Figures 2 and 3 summarise the results of the tailored quality assessment of the included studies for CYFRA 21-1 and MMP-9 respectively utilizing the QUADAS-2 tool. (12) The figures show a summary of the risk of bias and applicability concerns by the authors' judgement in each of the four domains for each included study (Appendix 3 includes comprehensive quality assessment performed for each study).

166

None of the included studies could be classified as being at low risk of bias for all four domains. Patient selection was considered as "high" risk of bias in all of the studies, which was mainly due to the method of patients' enrolment (13), the nature of the study design (13-18), and implementing inappropriate exclusions. $(13,14,16)$

171

172 The index test was considered to be at "low" risk of bias in only one study (18), "unclear" in one study (14), but "high" in 4 studies. $(13,15-17)$ The variation across the level of bias differs

174 due to insufficient details reported whether the results of the index test were interpreted without prior knowledge of the reference standard results; lack of pre-specification of a testpositive threshold; and statement of conflict of interest. Similarly, the reference standard

177 domain was considered to be at "low" risk of bias in only one study (18), and "unclear" in the 178 other 5 studies. All of the 5 studies were judged as "unclear" due to the inadequate reporting 179 of whether the biopsy and histopathological diagnoses were made without any prior 
knowledge of the index test results. Additionally, 3 studies $(13,16,17)$ failed to comprehensively report the details of the reference standard.

182

183 The flow and timing domain was considered as "unclear" risk of bias across all the studies due

184 to insufficient details reported regarding the interval periods between the index and reference standard (inadequately reported in all six studies), whether all patients received the same reference standard (13), and if all patients have been included in the analysis. (14) Only 3 studies $(15,16,18)$ were assessed as "low" concern for applicability according to patient selection, the index test and the reference standard. The remaining three studies were assessed as "unclear" concern for applicability due to lack of details regarding the patient selection (14) and conduct of the reference standard. $(13,17)$

\subsection{Findings}

193 The sensitivity and specificity of CYFRA $21-1$ (with $95 \% \mathrm{Cl}$ ) ranged from 0.84 (0.75 to 0.91 ) to 0.94 (0.83 to 0.99$)$ and $0.84(0.71$ to 0.93$)$ to 0.96 (0.80 to 1.00$)$ respectively. Whereas the sensitivity and specificity of MMP-9 (with $95 \% \mathrm{Cl}$ ) ranged from 0.76 (0.67 to 0.83 ) to 1.00 (0.78 to 1.00$)$ and specificity values from $0.27(0.12$ to 0.46$)$ to 1.00 (0.78 to 1.00$)$. Table 2 shows a

197 summary of the data extracted from the included studies. The overall quality of the included studies for both CYFRA 21-1 and MMP-9 was poor and mainly limited by selective patient selection, a lack of assessors to the results of previous assessments, and small sample sizes. MMP-9 studies. 
Due to the small number of studies, differences in index test techniques, and variability of positivity thresholds across the studies, meta-analysis was not conducted. Results were presented graphically as coupled forest plots for each salivary biomarker as shown in figures 4 and 5.

\section{DISCUSSION}

210

\subsection{Study Design, Methodology, and Reporting}

212 Most of the studies included were at high risk of selection bias arising from the use of a twoparticipants alongside healthy (disease-free), age-and-gender-matched cases, or both (healthy age-and-gender-matched cases). One study recruited a sample of participants with OSCC and

216 healthy or low-risk PMDs cases, which is a more representative spectrum of diseased and non-

217 diseased individuals in the population. (18)

In addition, patients' sampling and/or recruitment into the studies were insufficiently reported. Only Yu study has sufficiently reported the patient selection process, which was randomly selected. (18) Moreover, inappropriate exclusion criteria were applied in some of the included studies, such as excluding patients with chronic inflammatory diseases, autoimmune disorders, or individuals with history of consumption of drugs with anticholinergic effects, which all could be within a spectrum of common diseases and drugs used with patients presenting in clinical setting; thus questioning the validity was inevitable. 
227 All studies used a biopsy and histopathological examination as a reference standard and a

228 salivary analysis, with different techniques, as an index test. However, insufficient detail

229 provided and lack of clarity in reporting the studies made it difficult to assess the risk of bias.

230 Therefore, the use of STARD (19) checklist in reporting the primary studies could have

231 facilitated quality appraisal.

232

233 Across all the studies included, different thresholds values for the classification of disease-

234 positive were used; only one study used a pre-specified cut-off (18), and one study (14)

235 incompletely reported the process of cut-off value determination. Selecting the cut-off values

236 after performing the test to maximise the test performance can impact the accuracy estimates

237 especially in small studies.(19)

238

239 In terms of the conditions and methods of saliva sample collection, process, and storage,

240 there was no particular standard method agreed and followed across the included studies.

241 Without process standardization, comparing, and validating the studies for OSCC salivary

242 biomarkers would be difficult.(20)

243

\section{$244 \quad 4.2$ Geographical Impact}

245 The CYFRA-21-1 studies (13-15) were solely conducted in India, while the MMP-9 studies (16-

246 18) were conducted in different geographical locations, namely Egypt, Germany, and Taiwan.

247 The sensitivity estimates for the CYFRA 21-1 studies were similar, as were the specificity

248 estimates, whereas the sensitivity and specificity from the MMP-9 studies were more

249 heterogeneous.. It is important to bear in mind that India alone accounts for a fifth of all OC

250 cases worldwide and all OC cases were developed from potentially malignant disorders seen 
in patients including betel quid users. $(21,22)$ Studies showed that chemicals in betel quid have cytotoxic and genotoxic effects on mucosal epithelial cells due to the generation of reactive oxygen species (ROS), genetic damage, and micronuclei formation. (23)

254

Csősz et al. (24) argued that protein biomarkers that were identified in one population may not necessarily be suitable in another population; this argument was supported by some studies that identified IL-8, S100A9, and catalase as biomarkers in certain countries but not in others. It has been also suggested that applying world-wide general protein biomarkers for OSCC detection would be very difficult, thus, the need for conducting population-tailored proteomics studies should be emphasized. (24)

\subsection{Biomarkers Expression}

Saliva as a diagnostic fluid has been shown to manifest altered expression of biomarkers not only in OSCC but in various oral and systemic diseases. (25-29) Historically, serum CYFRA 21-1 was originally being investigated as a biomarker for non-small-cell lung carcinoma (NSCLC) then evaluated in other malignant and non-malignant diseases. (30-32) Several studies have reported the usefulness of serum CYFRA 21-1 as a biomarker in different conditions including breast cancer, gastric cancer, intrahepatic cholangiocarcinoma (ICC), colorectal cancer, cervical cancer, urinary bladder cancer, and malignant mesothelioma. (33-41) In the head and neck region, serum CYFRA 21-1 could also be a useful biomarker in nasopharyngeal carcinoma, hypopharyngeal carcinoma, oropharyngeal cancer, and OSCC.(14, 15, 41, 42) Malhotra (14) and Rajkumar (15) studies, which are both included in this review, have evaluated the correlation between the serum and salivary CYFRA 21-1 in OSCC. Rajkumar (15) found that 
salivary CYFRA $21-1$ levels were threefold higher when compared to serum levels $(P<0.001)$ and increased in stage IV in both serum and saliva. Whereas Malhotra (14) found a significant correlation between serum and salivary CYFRA 21-1 $(P=0.002)$ and showed that both salivary and serum CYFRA 21-1 levels were significantly elevated in grade II OSCC compared to grade I. At the same time, previous studies showed various results regarding the differences in CYFRA 21-1 levels according to the clinical stages (43-45) while other studies have claimed no correlation. $(46,47)$

Similarly, MMP-9 altered expression in tissues and biofluids has also been evaluated in extensive number of studies that explored its role in different diseases and malignancies. Studies showed that tissue MMP-9 level was elevated in many types of malignancies such as SCC of the uterine cervix, ovarian cancer, endometrial cancer, breast cancer, adenocarcinoma of the lung, NSCLC, papillary thyroid cancer, gastric cancer, colorectal cancer, and salivary gland cancer. (48-57) While serum MMP-9 was also elevated in breast cancer, pancreatic ductal adenocarcinoma, and NSCLC. (58-61) Moreover, MMP-9 can be found in urine, plasma and cerebrospinal fluid in various types of malignancies, and was found to be elevated in rheumatoid arthritis in gingival crevicular fluid (GCF) as well. $(62,63)$ In the head and neck region, MMP-9 is shown to be overexpressed not only in saliva but in plasma, tissue and GCF in oral PMDs such as oral lichen planus, leukoplakia, oral submucous fibrosis, and chronic periodontitis. (63-67)

Since CYFRA 21-1 and MMP-9 can be expressed in various cellular stages and diseases such as inflammatory diseases and malignancies, it is important to explore their effectiveness as diagnostic biomarkers in each condition and to correlate their levels in different biofluids. Due 
to the nature of the existence of these biomarkers in various conditions, it is extremely challenging to consider them specific biomarkers for oral cancer. Therefore, the ability of these biomarkers to distinguish oral cancer from other co-morbidities is the keystone for the sake of clinical usefulness and future applications and development. One of the ideas that could help in reaching this goal is combining multiple biomarkers as demonstrated in several studies, however, further studies are needed to investigate the effectiveness of multiple marker combinations. $(24,68-70)$

In conclusion, salivary biomarkers in general may have a great potential toward the early detection of OSCC and other diseases as well. However, due to the presence of biases and other limitations in the studies reviewed, there is no conclusive evidence of value of singular salivary CYFRA 21-1 or MMP-9 analyses as screening tools for OSCC at the present time.

Therefore, further standardised diagnostic test accuracy studies which minimise potential sources of bias through rigorous design, conduct and reporting are needed. Reporting guidelines for primary diagnostic studies (71) should be strictly followed, and studies should

314 address all potential sources of bias and applicability concerns as indicated in the QUADAS-2 tool. (12) Future research should focus on the accuracy of the current potential salivary

316 biomarkers in the detection of OSCC with clear and robust methodology. Futures studies in

317 oral cancer could be informed by studies of the diagnostic accuracy of combined salivary

318 biomarkers panels in other diseases, which could have similar singular biomarkers' altered expressions. 
Declarations

323 Funding: No funding

324 Competing Interests: There are no conflicts of interest

325 Ethical Approval: Ethical approval was not needed

326 Patient Consent: Patient consent was not needed 
1. BDA. Opportunistic Oral Cancer Screening: A Management Strategy for Dental Practice London: British Dental Association; 2000 [Available from: https://bda.org/dcps/policyandcampaigns/science-health/science-healthcampaigns/Documents/mouth cancer.pdf.

333 2. Macey R, Walsh T, Brocklehurst P, Kerr AR, Liu JLY, Lingen MW, et al. Diagnostic tests for oral cancer and potentially malignant disorders in patients presenting with clinically evident lesions. Cochrane Database of Systematic Reviews. 2015(5).

3. Lee JM, Garon E, Wong DT. Salivary diagnostics. Orthod Craniofac Res. 2009;12(3):20611.

4. Yoshizawa JM, Schafer CA, Schafer JJ, Farrell JJ, Paster BJ, Wong DTW. Salivary biomarkers: toward future clinical and diagnostic utilities. Clin Microbiol Rev. 2013;26(4):78191.

341 5. Stuani VT, Rubira CMF, Sant'Ana ACP, Santos PSS. Salivary biomarkers as tools for oral squamous cell carcinoma diagnosis: A systematic review. Head \& Neck. 2017;39(4):797-811. 6. Gualtero DF, Suarez Castillo A. Biomarkers in saliva for the detection of oral squamous cell carcinoma and their potential use for early diagnosis: a systematic review. Acta Odontologica Scandinavica. 2016;74(3):170-7.

346 7. Rutjes AWS, Reitsma JB, Vandenbroucke JP, Glas AS, Bossuyt PMM. Case-Control and

347 Two-Gate Designs in Diagnostic Accuracy Studies. Clinical Chemistry. 2005;51(8):1335-41.

348 8. Reitsma J, Rutjes A, Whiting P, Vlassov V, Leeflang M, Deeks J. Assessing Methodological Quality. 2009. In: Cochrane Handbook for Systematic Reviews of Diagnostic

350 Test Accuracy [Internet]. Cochrane 1.0.0. Available from:

351 https://methods.cochrane.org/sites/methods.cochrane.org.sdt/files/public/uploads/ch09 Oct 352 09.pdf.

353 9. Yeung CA. Referrals to dentists by GPs could delay diagnosis of oral cancer. BMJ. 354 2017;356:i6784.

355 10. Moher D, Liberati A, Tetzlaff J, Altman DG, Group P. Preferred reporting items for 356 systematic reviews and meta-analyses: the PRISMA statement. PLoS Med.

357 2009;6(7):e1000097-e.

358 11. Cochrane. RevMan 5.3 User Guide 2018 [Available from:

359 http://community.cochrane.org/sites/default/files/uploads/inline360 files/RevMan 5.3 User Guide.pdf.

361 12. Whiting PF, Rutjes AWS, Westwood ME, Mallett S, Deeks JJ, Reitsma JB, et al. QUADAS2: A Revised Tool for the Quality Assessment of Diagnostic Accuracy Studies. Annals of Internal 363 Medicine. 2011;155(8):529-36.

364 13. Awasthi N. Role of salivary biomarkers in early detection of oral squamous cell carcinoma. Indian Journal of Pathology and Microbiology. 2017;60(4):464-8. 14. Malhotra R, Urs AB, Chakravarti A, Kumar S, Gupta VK, Mahajan B. Correlation of Cyfra 21-1 levels in saliva and serum with CK19 mRNA expression in oral squamous cell carcinoma. Tumor Biology. 2016;37(7):9263-71.

369 15. Rajkumar K, Ramya R, Nandhini G, Rajashree P, Ramesh Kumar A, Nirmala Anandan S. 370 Salivary and serum level of CYFRA 21-1 in oral precancer and oral squamous cell carcinoma.

371 Oral Diseases. 2015;21(1):90-6. 
16. Ghallab NA, Shaker OG. Serum and salivary levels of chemerin and MMP-9 in oral squamous cell carcinoma and oral premalignant lesions. Clin Oral Investig. 2017;21(3):937-47. 17. Peisker A, Raschke GF, Fahmy MD, Guentsch A, Roshanghias K, Hennings J, et al. Salivary MMP-9 in the detection of oral squamous cell carcinoma. Med Oral Patol Oral Cir Bucal. 2017;22(3):e270-e5.

18. Yu J-S, Chen Y-T, Chiang W-F, Hsiao Y-C, Chu L, See L-C, et al. Saliva protein biomarkers to detect oral squamous cell carcinoma in a high-risk population in Taiwan. Proceedings of the National Academy of Sciences. 2016;113(41):11549-54.

19. Cohen JF, Korevaar DA, Altman DG, Bruns DE, Gatsonis CA, Hooft L, et al. STARD 2015 guidelines for reporting diagnostic accuracy studies: explanation and elaboration. BMJ Open. 2016;6(11):e012799.

20. Cheng Y-SL, Rees T, Wright J. A review of research on salivary biomarkers for oral cancer detection. Clin Transl Med. 2014;3(1):3-.

21. Sankaranarayanan R, Ramadas K, Amarasinghe $H$, Subramanian S, Johnson N. Oral Cancer: Prevention, Early Detection, and Treatment. In: Gelband H, Jha P, Sankaranarayanan $\mathrm{R}$, Horton S, editors. Cancer: Disease Control Priorities, Third Edition (Volume 3). Washington (DC)2015.

22. Gupta PC, Mehta FS, Daftary DK, Pindborg JJ, Bhonsle RB, Jalnawalla PN, et al. Incidence rates of oral cancer and natural history of oral precancerous lesions in a 10-year follow-up study of Indian villagers. Community Dent Oral Epidemiol. 1980;8(6):283-333. 23. Pervez S, Abro B. Oral Cancer and Chewing Habits. In: Moustafa A-EA, editor. Development of Oral Cancer. Switzerland: Springer International Publishing; 2017. p. 115-32. 24. Csősz É, Lábiscsák P, Kalló G, Márkus B, Emri M, Szabó A, et al. Proteomics investigation of OSCC-specific salivary biomarkers in a Hungarian population highlights the importance of identification of population-tailored biomarkers. PLOS ONE. 2017;12(5):e0177282.

25. Buczko P, Zalewska A, Szarmach I. Saliva and oxidative stress in oral cavity and in some systemic disorders. J Physiol Pharmacol. 2015;66(1):3-9.

26. Zhang L, Farrell JJ, Zhou H, Elashoff D, Akin D, Park N-H, et al. Salivary transcriptomic biomarkers for detection of resectable pancreatic cancer. Gastroenterology. 2010;138(3):94957.e577.

27. Streckfus CF, Mayorga-Wark O, Arreola D, Edwards C, Bigler L, Dubinsky WP. Breast Cancer Related Proteins Are Present in Saliva and Are Modulated Secondary to Ductal Carcinoma In Situ of the Breast. Cancer Investigation. 2008;26(2):159-67.

28. Li X, Yang T, Lin J. Spectral analysis of human saliva for detection of lung cancer using surface-enhanced Raman spectroscopy. J Biomed Opt. 2012;17(3):037003.

29. Lee YH, Kim JH, Zhou H, Kim BW, Wong DT. Salivary transcriptomic biomarkers for detection of ovarian cancer: for serous papillary adenocarcinoma. J Mol Med (Berl). 2012;90(4):427-34.

30. H B, D B, B O, D J, A D. Technical evaluation of a new automated tumor marker assay: the Enzymun-Test CYFRA 21-1. In: Klapdor R (ed) Tumor associated antigens, oncogenes, receptors, cytokines in tumor diagnosis and therapy at the beginning of the 90s. Zuckschwerdt, München. 1992:137-8.

31. Stieber $P$, Hasholzner $U$, Bodenmuller $H$, Nagel D, Sunder-Plassmann L, Dienemann $H$, et al. CYFRA 21-1. A new marker in lung cancer. Cancer. 1993;72(3):707-13. 

Marker, CYFRA21-1, in Malignant and Nonmalignant Diseases. Tumor Biology. 1994;15(6):31825. (cytokeratin-19 fragments) is a useful tumour marker for detecting disease relapse and assessing treatment efficacy in breast cancer. British journal of cancer. 2004;91(5):873-8. 34. Rodríguez CA, Cruz JJ, Martín T, Gómez A, Olaverri A, Hernández M. Serum CYFRA 21-1 is one of the most reliable tumor markers for breast carcinoma. Cancer. 2002;95(3):670-1. 35. Choi JS, Han KH, Kim E-K, Moon HJ, Yoon JH, Kim MJ. Fine-needle aspirate CYFRA 21-1, an innovative new marker for diagnosis of axillary lymph node metastasis in breast cancer patients. Medicine (Baltimore). 2015;94(19):e811-e. 36. Nakata $B, C$ Chung $Y S$, Kato $Y$, Ogawa $M$, Ogawa $Y$, Inui $A$, et al. Clinical significance of serum CYFRA 21-1 in gastric cancer. British journal of cancer. 1996;73(12):1529-32. 37. Uenishi T, Kubo S, Hirohashi K, Tanaka H, Shuto T, Yamamoto T, et al. Cytokeratin-19 fragments in serum (CYFRA 21-1) as a marker in primary liver cancer. British journal of cancer. 2003;88(12):1894-9.

38. Miyashita T, Nishimura G, Michiwa Y, Sato T, Tsugawa K, Fushida S, et al. [Clinical usefulness of serum CYFRA21-1 in colorectal cancer]. Gan To Kagaku Ryoho.

435

436

437 1996;23(12):1693-6.

39. Suzuki Y, Nakano T, Ohno T, Abe A, Morita S, Tsujii H. Serum CYFRA 21-1 in cervical cancer patients treated with radiation therapy. J Cancer Res Clin Oncol. 2000;126(6):332-6. 40. Stieber P, Schmeller N, Schambeck C, Hofmann K, Reiter W, Hasholzner U, et al. Clinical relevance of CYFRA 21-1, TPA-IRMA and TPA-LIA-mat in urinary bladder cancer. Anticancer Res. 1996;16(6B):3793-8.

441

41. Bonfrer JM, Schouwink JH, Korse CM, Baas P. Cyfra 21-1 and TPA as markers in malignant mesothelioma. Anticancer Res. 1997;17(4B):2971-3.

443

444

445

446

447

42. Sawant SS, Zingde SM, Vaidya MM. Cytokeratin fragments in the serum: their utility for the management of oral cancer. Oral Oncol. 2008;44(8):722-32.

43. Ceruse P, Rabilloud M, Charrie A, Dubreuil C, Disant F. Study of cyfra 21-1, a tumor marker, in head and neck squamous cell carcinoma. Ann Otol Rhinol Laryngol. 2005;114(10):768-76.

448 44. Deng YF, Chen P, Lin YZ, Le JZ, Wu XL, Yu MQ, et al. Analytical and clinical evaluation of 449 CYFRA 21-1 by electrochemiluminescent immunoassay in head and neck squamous cell carcinoma. J Laryngol Otol. 2003;117(3):190-4.

45. Doweck I, Barak M, Greenberg E, Uri N, Kellner J, Lurie M, et al. Cyfra 21-1. A new potential tumor marker for squamous cell carcinoma of head and neck. Arch Otolaryngol Head Neck Surg. 1995;121(2):177-81.

46. Zhong LP, Zhang CP, Zheng JW, Li J, Chen WT, Zhang ZY. Increased Cyfra 21-1 concentration in saliva from primary oral squamous cell carcinoma patients. Arch Oral Biol. 2007;52(11):1079-87.

457 47. BONGERS V, BRAAKHUIS BJM, SNOW GB. Circulating fragments of cytokeratin 19 in 458 patients with head and neck squamous cell carcinoma. Clinical Otolaryngology \& Allied 459 Sciences. 1995;20(5):479-82.

460 48. Yu W, Liu J, Xiong X, Ai Y, Wang H. Expression of MMP9 and CD147 in invasive 461 squamous cell carcinoma of the uterine cervix and their implication. Pathol Res Pract. 462 2009;205(10):709-15. 
49. Davidson B, Goldberg I, Berner A, Kristensen GB, Reich R. EMMPRIN (extracellular matrix metalloproteinase inducer) is a novel marker of poor outcome in serous ovarian carcinoma. Clin Exp Metastasis. 2003;20(2):161-9.

50. Aglund K, Rauvala M, Puistola U, Angstrom T, Turpeenniemi-Hujanen T, Zackrisson B, et al. Gelatinases A and B (MMP-2 and MMP-9) in endometrial cancer-MMP-9 correlates to the grade and the stage. Gynecol Oncol. 2004;94(3):699-704.

51. McGowan PM, Duffy MJ. Matrix metalloproteinase expression and outcome in patients with breast cancer: analysis of a published database. Ann Oncol. 2008;19(9):1566-72.

52. Kodate $M$, Kasai T, Hashimoto $H$, Yasumoto $K$, I wata $Y$, Manabe $H$. Expression of matrix metalloproteinase (gelatinase) in T1 adenocarcinoma of the lung. Pathol Int. 1997;47(7):4619.

53. Cox G, Jones JL, O'Byrne KJ. Matrix metalloproteinase 9 and the epidermal growth factor signal pathway in operable non-small cell lung cancer. Clin Cancer Res. 2000;6(6):234955.

54. Maeta $\mathrm{H}$, Ohgi $\mathrm{S}$, Terada T. Protein expression of matrix metalloproteinases 2 and 9 and tissue inhibitors of metalloproteinase 1 and 2 in papillary thyroid carcinomas. Virchows Arch. 2001;438(2):121-8.

55. Sier CF, Kubben FJ, Ganesh S, Heerding MM, Griffioen G, Hanemaaijer R, et al. Tissue levels of matrix metalloproteinases MMP-2 and MMP-9 are related to the overall survival of patients with gastric carcinoma. Br J Cancer. 1996;74(3):413-7.

56. Zeng ZS, Huang Y, Cohen AM, Guillem JG. Prediction of colorectal cancer relapse and survival via tissue RNA levels of matrix metalloproteinase-9. J Clin Oncol. 1996;14(12):3133-40. 57. Luukkaa H, Klemi $P$, Hirsimaki $P$, Vahlberg $T$, Kivisaari $A$, Kahari VM, et al. Matrix metalloproteinase (MMP)-7 in salivary gland cancer. Acta Oncol. 2010;49(1):85-90.

58. Wu ZS, Wu Q, Yang JH, Wang HQ, Ding XD, Yang F, et al. Prognostic significance of MMP-9 and TIMP-1 serum and tissue expression in breast cancer. Int J Cancer. 2008;122(9):2050-6.

59. La Rocca G, Pucci-Minafra I, Marrazzo A, Taormina P, Minafra S. Zymographic detection and clinical correlations of MMP-2 and MMP-9 in breast cancer sera. Br J Cancer. 2004;90(7):1414-21.

60. Tian M, Cui YZ, Song GH, Zong MJ, Zhou XY, Chen Y, et al. Proteomic analysis identifies MMP-9, DJ-1 and A1BG as overexpressed proteins in pancreatic juice from pancreatic ductal adenocarcinoma patients. BMC Cancer. 2008;8:241.

61. Jumper C, Cobos E, Lox C. Determination of the serum matrix metalloproteinase-9 (MMP-9) and tissue inhibitor of matrix metalloproteinase-1 (TIMP-1) in patients with either advanced small-cell lung cancer or non-small-cell lung cancer prior to treatment. Respir Med. 2004;98(2):173-7.

62. Roy R, Yang J, Moses MA. Matrix metalloproteinases as novel biomarkers and potential therapeutic targets in human cancer. J Clin Oncol. 2009;27(31):5287-97.

63. Silosi I, Cojocaru M, Foia L, Boldeanu MV, Petrescu F, Surlin P, et al. Significance of circulating and crevicular matrix metalloproteinase- 9 in rheumatoid arthritis-chronic periodontitis association. J Immunol Res. 2015;2015:218060.

64. Singh RD, Nilayangode H, Patel JB, Shah FD, Shukla SN, Shah PM, et al. Combined evaluation of matrix metalloproteinases and their inhibitors has better clinical utility in oral cancer. Int J Biol Markers. 2011;26(1):27-36. 
508 65. P OC, Rhys-Evans PH, Eccles SA. Expression of matrix metalloproteinases and their

509 inhibitors correlates with invasion and metastasis in squamous cell carcinoma of the head and

510 neck. Arch Otolaryngol Head Neck Surg. 2001;127(7):813-20.

511 66. Venugopal A, Uma Maheswari TN. Expression of matrix metalloproteinase-9 in oral

512 potentially malignant disorders: A systematic review. J Oral Maxillofac Pathol. 2016;20(3):474-

5139.

514 67. Makela M, Salo T, Uitto VJ, Larjava H. Matrix metalloproteinases (MMP-2 and MMP-9)

515 of the oral cavity: cellular origin and relationship to periodontal status. J Dent Res.

516 1994;73(8):1397-406.

517 68. Heawchaiyaphum C, Pientong C, Phusingha $P$, Vatanasapt $P$, Promthet $S$, Daduang J, et

518 al. Peroxiredoxin-2 and zinc-alpha-2-glycoprotein as potentially combined novel salivary

519 biomarkers for early detection of oral squamous cell carcinoma using proteomic approaches. J

520 Proteomics. 2018;173:52-61.

521 69. Ishikawa S, Sugimoto M, Kitabatake K, Sugano A, Nakamura M, Kaneko M, et al.

522 Identification of salivary metabolomic biomarkers for oral cancer screening. Sci Rep.

$523 \quad 2016 ; 6: 31520$.

524 70. Wei J, Xie G, Zhou Z, Shi P, Qiu Y, Zheng X, et al. Salivary metabolite signatures of oral

525 cancer and leukoplakia. Int J Cancer. 2011;129(9):2207-17.

526 71. Bossuyt PM, Reitsma JB, Bruns DE, Gatsonis CA, Glasziou PP, Irwig L, et al. STARD 2015:

527 an updated list of essential items for reporting diagnostic accuracy studies. BMJ : British

528 Medical Journal. 2015;351:h5527. 


\begin{tabular}{|c|c|}
\hline \multicolumn{2}{|c|}{ Author Queries } \\
\hline [Au?1] & Kuwait phone number given with UK address. Is this correct? \\
\hline [Au?2] & $\begin{array}{l}\text { "...180 ( } \underline{54 \%}) \text { patients in the CYFRA } 21-1 \text { studies..." } \\
\text { Should this be } 51 \%(180 / 355) ?\end{array}$ \\
\hline [Au?3] & $\begin{array}{l}\text { "... and mainly limited by selective patient selection, a lack of assessors to } \\
\text { the results of previous assessments, and small sample sizes." } \\
\text { Clarification required. Should this read "a lack of blinding of the } \\
\text { assessors to the results of previous assessments"? }\end{array}$ \\
\hline [Au?4] & $\begin{array}{l}\text { "All but one of the included studies recruited OSCC participants } \\
\text { alongside healthy (disease-free), age and sex-matched cases, or both } \\
\text { (healthy age and sex-matched cases)." } \\
\text { Clarification required. Should this read "alongside healthy (disease-free) } \\
\text { controls, age and sex-matched controls, or both healthy and age and sex- } \\
\text { matched controls"? }\end{array}$ \\
\hline [Au?5] & Please provide the date on which accessibility was verified. \\
\hline [Au?6] & Ref. 1: please check URL. Cannot access the document. \\
\hline [Au?7] & $\begin{array}{l}\text { References list. All author names must be listed. Please provide the } \\
\text { missing names for references marked with this query. }\end{array}$ \\
\hline [Au?8] & Ref. 21: please provide the name of the publisher. \\
\hline [Au?9] & Ref. 30: please list the author names in the correct format. \\
\hline [Au?10] & Ref. 65: please check author name. \\
\hline [Au?11] & $\begin{array}{l}\text { Fig. 1: all the "of" (e.g. " } 250 \text { of records") should be deleted (in three } \\
\text { places); "No Control group", should be "No control group" (for } \\
\text { consistency). }\end{array}$ \\
\hline [Au?12] & $\begin{array}{l}\text { Figs. } 2 \text { and 4: "Awashti" should be "Awasthi"; "Malhotre" should be } \\
\text { "Malhotra". }\end{array}$ \\
\hline [Au?13] & $\begin{array}{l}\text { Table 2: reference numbers have been changed to agree with the text and } \\
\text { list. Please confirm that they are correct. }\end{array}$ \\
\hline [Au?14] & $\begin{array}{l}\text { Table 2: please check that footnote ' } b \text { ' is correct. (This has been } \\
\text { changed.) }\end{array}$ \\
\hline
\end{tabular}


Author e-mail addresses: Ahmad M. AlAli, alali.a@hotmail.com; Tanya Walsh, tanya.walsh@manchester.ac.uk; Massimo Maranzano, massimo.maranzano@manchester.ac.uk

Running heads:

Recto: Biomarkers for the detection of OSCC

Verso: AlAli et al.

Correspondence:

Ahmad M. AlAli, Division of Dentistry, School of Medical Sciences, Coupland 3 Building, The University of Manchester, Manchester, M13 9PL, United Kingdom. Tel: +96597972742 [Au?1]. E-mail: Alali.a@hotmail.com

[ARTICLE TYPE - SYSTEMATIC REVIEW, HEAD AND NECK

ONCOLOGY]

CYFRA 21-1 and MMP-9 as salivary biomarkers for the detection of oral squamous cell carcinoma: a systematic review of diagnostic test accuracy

\author{
Ahmad M. AlAli' ${ }^{1,2}$, Tanya Walsh ${ }^{1}$, Massimo Maranzano ${ }^{3}$ \\ ${ }^{1}$ Division of Dentistry, School of Medical Sciences, Faculty of Biology, Medicine and \\ Health, The University of Manchester, Manchester, United Kingdom
}


${ }^{2}$ Oral and Maxillofacial Department, Al-Adan Specialised Dental Centre, Ministry of Health, Kuwait

${ }^{3}$ Oral and Maxillofacial and Facial Plastic Surgery Department, Manchester University NHS Foundation Trust, Manchester, United Kingdom

\begin{abstract}
Tissue biopsy with histopathological examination is still considered the gold standard to diagnose oral squamous cell carcinoma (OSCC). This systematic review explored the diagnostic test accuracy of two salivary biomarkers in adults suspected of OSCC. The Cochrane Library, MEDLINE, and Embase databases were searched for clinical studies evaluating the diagnostic accuracy of salivary biomarkers in detecting OSCC. Studies were eligible for inclusion if only singular salivary biomarkers were evaluated in three or more studies. Studies investigating combined salivary biomarkers or assessing patients with oral potentially malignant disorders only were excluded. The reporting of the review follows the PRISMA checklist. Six studies, recruiting 775 participants, were included in this review for only two salivary biomarkers, cytokeratin 19 fragment (CYFRA 21-1) and matrix metalloproteinase 9 (MMP-9). The sensitivity and specificity (with 95\% confidence intervals) for CYFRA 21-1 studies ranged from $0.84(0.75-0.91)$ to $0.94(0.83-0.99)$ and from $0.84(0.71-0.93)$ to 0.96 (0.80-1.00), respectively. In MMP-9 studies, sensitivity (with 95\% confidence intervals) ranged from $0.76(0.67-0.83)$ to $1.00(0.78-1.00)$ and specificity from 0.27 $(0.12-0.46)$ to $1.00(0.78-1.00)$. The overall quality of the included studies was poor. Due to a lack of strong and high-quality evidence, considerable uncertainty remains surrounding the use of singular salivary biomarkers for the detection of OSCC.
\end{abstract}


Key words: oral cancer, oral squamous cell carcinoma, OSCC, salivary biomarkers, CYFRA 21-1, MMP-9

\section{Introduction}

Many different techniques and tests delivered in a variety of settings are available for the detection of oral squamous cell carcinoma (OSCC). Conventional oral examination performed by a general dental practitioner has traditionally been recommended by various health and medical/dental organizations as a part of oral cancer screening programmes, e.g., the British Dental Association ${ }^{1}$. A Cochrane systematic review has evaluated the diagnostic accuracy of a variety of tests as adjunct tests to the conventional oral examination in a dental setting, including vital staining, oral cytology, light-based detection, and oral spectroscopy in patients presenting with clinically evident lesions ${ }^{2}$. The results showed that cytology tests appeared to have the greatest potential and warranted further investigation. However, the overall quality of the evidence was variable, with insufficient evidence to justify the replacement of the current 'gold standard' diagnostic test of scalpel biopsy with histopathological examination in addition to the conventional oral examination.

Comparatively, saliva, also known as the 'mirror of the body', is an easy fluid to collect for bioanalysis. Sample/specimen collection is non-invasive, inexpensive, and simple, which makes it an ideal method for diagnostic purposes ${ }^{3}$. Saliva contains an extensive number of compounds, is safe to handle and store, does not clot, and as such, it is deemed a promising diagnostic biofluid ${ }^{4}$. Two systematic reviews have evaluated the performance of a wide range of salivary biomarkers (biomarker 
expression) in OSCC ${ }^{5,6}$. However, these systematic reviews mainly included 'casecontrol' type accuracy studies, which can be prone to bias. Studies that compare altered expression of a specific salivary biomarker between 'cases' with OSCC and healthy 'control' participants can deliver misleading results when the methods of participant recruitment are not taken into consideration ${ }^{7}$. If participants representing only subgroups of the spectrum of disease and spectrum of non-diseased are included, the resulting estimates of diagnostic test accuracy may not be applicable to the clinical question $^{8}$.

OSCC is an increasing disease globally. Several factors have been implicated in the development of the disease, such as tobacco, betel quid, and alcohol use, as well as others like human papillomavirus (HPV) and Epstein-Barr virus (EBV) infections. The survival rate of individuals with OSCC is approximately $90 \%$ when detected early, compared to only $50 \%$ after delayed diagnosis ${ }^{9}$. Hence, both prevention and early detection of disease are crucial in reducing OSCC mortality.

The aim of this systematic review was to identify and summarize the diagnostic accuracy of salivary biomarkers currently being used in the detection of OSCC in adults. The reporting of the review follows the PRISMA checklist ${ }^{10}$.

\section{Materials and methods}

\section{Study criteria}

Studies were eligible for inclusion in the review if they evaluated salivary biomarkers and reported measures of diagnostic test accuracy such as sensitivity and specificity in 
detecting OSCC in adults (age $\geq 16$ years) suspected of having OSCC, with no prior treatment such as chemotherapy or radiotherapy.

\section{Inclusion and exclusion criteria}

Only studies evaluating the performance of singular salivary biomarkers (index test) against any type of tissue biopsy with histopathological examination (reference standard) for the diagnosis of OSCC were eligible for inclusion. Studies were eligible for inclusion in the review if only singular salivary biomarkers were evaluated and where the performance of a salivary biomarker was assessed in three or more studies. Studies investigating combined salivary biomarkers or assessing patients with oral potentially malignant disorders (PMDs) only were excluded.

\section{Search protocol and study selection}

An electronic search was performed on June 14, 2018 for studies published within the last 5 years (from 2014 to 2018) using the following databases: Cochrane Library, MEDLINE via OVID, and Embase via OVID. The search strategy used was as follows: (oral cancer OR mouth cancer OR oral squamous cell carcinoma OR OSCC).mp AND (diagnos* OR detect*).mp AND (saliva* AND (marker* OR biomarker* OR test)).mp. Following the removal of duplicates, the titles and/or abstracts of the retrieved records were screened for relevancy, and full-text articles were obtained if necessary. Next, full-text articles were assessed for eligibility. Studies were included following consensus among all three authors. 


\section{Data extraction}

The following data were extracted from each included study: (1) study information and setting (country, design, sample size, test used), (2) type of salivary biomarker, (3) study results: true-positive (sensitivity) and true-negative (specificity), and positive and negative predictive values (PPV and NPV) where reported. A $2 \times 2$ table was constructed for each study (reference standard against the index test) using Review Manager $5.3^{11}$. The corresponding author of a study was contacted via email where further information or explanation was needed.

\section{Assessment of methodological quality}

Using a tailored QUADAS-2 tool, the quality of the included studies (risk of bias and applicability concerns) was assessed through its four domains: patient selection, index test, reference standard, and flow and timing of participants through the study ${ }^{12}$. The indicators of the assessment of quality (QUADAS-2) are summarized in Table 1, as adapted from Macey et al. ${ }^{2}$. The results were then graphically presented using $\operatorname{RevMan}^{11}$.

\section{[Table 1 here]}

\section{Statistical analysis and data synthesis}

The target condition (disease positive) was OSCC. The true-positive, true-negative, false-positive, and false-negative values were used to construct $2 \times 2$ tables for each 
study $^{12}$. The diagnostic test accuracy results for each biomarker were expressed as sensitivity and specificity with 95\% confidence intervals (CI). Results were presented graphically as a coupled forest plot for each salivary biomarker.

\section{Results}

Following the removal of duplicates, the electronic search yielded a total of 250 records, of which 224 were excluded; 26 were further assessed for eligibility (Supplementary Material Appendix 1). Only six studies met the inclusion criteria in this review, as illustrated in the PRISMA flow diagram in Fig. $1^{10}$. The main reason for exclusion was the low number of studies that investigated each salivary biomarker (Supplementary Material Appendix 2). Only if a biomarker had three or more studies was it eligible to be included in the review. Thus, only six studies reporting the diagnostic accuracy of salivary biomarkers cytokeratin 19 fragment (CYFRA 21-1) ${ }^{13-}$ 15 and matrix metalloproteinase 9 (MMP-9) ${ }^{16-18}$ in detecting OSCC were included.

\section{[Figure 1 here]}

\section{Description of studies}

The included studies evaluated data from a total of 775 patients (355 patients for CYFRA 21-1 and 420 patients for MMP-9). Of the total 775 patients, 356 (46\%) were diagnosed with OSCC according to the reference standard of biopsy and histopathological examination: 180 (54\% [Au?2]) patients in the CYFRA 21-1 studies and 176 (42\%) patients in the MMP-9 studies. The remaining 419 patients were 
classed as disease-free or non-OSCC (175 patients for CYFRA 21-1 and 244 patients for MMP-9). The three CYFRA 21-1 studies were from India ${ }^{13-15}$, while the three MMP-9 studies were from Egypt ${ }^{16}$, Germany ${ }^{17}$, and Taiwan ${ }^{18}$. Salivary sample collection was conducted in a hospital setting (academic or dental/medical centre) between 2008 and 2014.

The classification and reporting of OSCC varied across studies, making metaanalysis inappropriate: two studies reported OSCC stages only (I-IV) ${ }^{16,18}$, one study reported OSCC grades only (1 and 2$)^{14}$, two studies reported OSCC stage (0-IVA) with grade $(1-3)^{13,15}$, and one study reported OSCC grade (1-4), but reported stages in the TNM system separately ${ }^{17}$.

\section{Methodological quality of included studies}

Figs. 2 and 3 summarize the results of the tailored quality assessment of the included studies for CYFRA 21-1 and MMP-9, respectively, utilizing the QUADAS-2 tool ${ }^{12}$. The figures show a summary of the risk of bias and applicability concerns according to the authors' judgement in each of the four domains for each included study (Supplementary Material Appendix 3 includes the comprehensive quality assessment performed for each study).

\section{[Figures 2 and 3 here]}

None of the included studies could be classified as being at low risk of bias for all four domains. Patient selection was considered as high risk of bias in all of the 
studies, which was mainly due to the method of patient enrolment ${ }^{13}$, the nature of the study design ${ }^{13-18}$, and implementing inappropriate exclusions ${ }^{13,14,16}$.

The index test was considered to be at low risk of bias in only one study ${ }^{18}$, unclear in one study ${ }^{14}$, but high in four studies ${ }^{13,15-17}$. The variation across the level of bias differed due to insufficient details reported as to whether the results of the index test were interpreted without prior knowledge of the reference standard results, lack of pre-specification of a test-positive threshold, and statement of conflict of interest. Similarly, the reference standard domain was considered to be at low risk of bias in only one study ${ }^{18}$, and unclear in the other five studies ${ }^{14-17}$. All of the five studies were judged as unclear due to the inadequate reporting of whether the biopsy and histopathological diagnoses were made without any prior knowledge of the index test results. Additionally, three studies failed to comprehensively report the details of the reference standard ${ }^{13,16,17}$.

The flow and timing domain was considered as having an unclear risk of bias across all of the studies due to insufficient details reported regarding the interval period between the index and reference standard (inadequately reported in all six studies), whether all patients received the same reference standard ${ }^{13}$, and whether all patients had been included in the analysis ${ }^{14}$. Only three studies were assessed as being of low concern for applicability according to patient selection, the index test, and the reference standard ${ }^{15,16,18}$. The remaining three studies were assessed as being of unclear concern for applicability due to the lack of detail regarding patient selection ${ }^{14}$ and conduct of the reference standard ${ }^{13,17}$.

\section{Findings}


The sensitivity and specificity of CYFRA 21-1 (with 95\% CI) ranged from 0.84 (0.75-0.91) to $0.94(0.83-0.99)$ and from $0.84(0.71-0.93)$ to $0.96(0.80-1.00)$, respectively. The sensitivity and specificity of MMP-9 (with 95\% CI) ranged from $0.76(0.67-0.83)$ to $1.00(0.78-1.00)$ and from $0.27(0.12-0.46)$ to $1.00(0.78-1.00)$, respectively. Table 2 shows a summary of the data extracted from the included studies. The overall quality of the included studies for both CYFRA 21-1 and MMP-9 was poor and mainly limited by selective patient selection, a lack of assessors to the results of previous assessments [Au?3], and small sample sizes. Table 3 shows a summary of the findings and quality assessment for both CYFRA 21-1 and MMP-9 studies.

\section{[Tables 2 and 3 here]}

Due to the small number of studies, differences in index test techniques, and variability of positivity thresholds across the studies, a meta-analysis was not conducted. The results are presented graphically as coupled forest plots for each salivary biomarker in Figs. 4 and 5.

[Figures 4 and 5 here]

\section{Discussion}

\section{Study design, methodology, and reporting}


Most of the studies included were at high risk of selection bias arising from the use of a two-gate or 'case-control' study design. All but one of the included studies recruited OSCC participants alongside healthy (disease-free), age and sex-matched cases, or both (healthy age and sex-matched cases) [Au?4]. One study recruited a sample of participants with OSCC and healthy or low-risk PMD cases, which is a more representative spectrum of diseased and non-diseased individuals in the population ${ }^{18}$. In addition, patient sampling and/or recruitment into the studies were insufficiently reported. Only the study by Yu et al. had sufficiently reported the patient selection process, which was randomly selected ${ }^{18}$. Moreover, inappropriate exclusion criteria were applied in some of the included studies, such as excluding patients with chronic inflammatory diseases, autoimmune disorders, or individuals with a history of consumption of drugs with anticholinergic effects, which all could be within a spectrum of common diseases and drugs used in patients presenting in the clinical setting; thus questioning the validity was inevitable.

All studies used a biopsy and histopathological examination as the reference standard and a salivary analysis (with different techniques) as the index test. However, insufficient detail provided and lack of clarity in reporting the studies made it difficult to assess the risk of bias. Therefore, use of the STARD ${ }^{19}$ checklist in reporting the primary studies could have facilitated the quality appraisal.

Across all of the studies included, different threshold values for the classification of disease-positive were used; only one study used a pre-specified cutoff $^{18}$, and one study incompletely reported the process of cut-off value determination ${ }^{14}$. Selecting the cut-off value after performing the test to maximize the test performance can impact the accuracy estimates, especially in small studies ${ }^{19}$. 
In terms of the conditions and methods of saliva sample collection, processing, and storage, there was no particular standard method agreed and followed across the included studies. Without process standardization, comparing and validating the studies for OSCC salivary biomarkers would be difficult ${ }^{20}$.

\section{Geographical impact}

The CYFRA 21-1 studies were solely conducted in India ${ }^{13-15}$, while the MMP-9 studies were conducted in different geographical locations, namely Egypt, Germany, and Taiwan ${ }^{16-18}$. The sensitivity estimates for the CYFRA 21-1 studies were similar, as were the specificity estimates, whereas the sensitivity and specificity from the MMP-9 studies were more heterogeneous. It is important to bear in mind that India alone accounts for a fifth of all oral cancer cases worldwide, and all oral cancer cases developed from potentially malignant disorders seen in patients including betel quid users $^{21,22}$. Studies have shown that chemicals in betel quid have cytotoxic and genotoxic effects on mucosal epithelial cells due to the generation of reactive oxygen species (ROS), genetic damage, and micronuclei formation ${ }^{23}$.

Csősz et al. argued that protein biomarkers that were identified in one population may not necessarily be suitable in another population ${ }^{24}$; this argument was supported by some studies that identified interleukin (IL)-8, S100A9, and catalase as biomarkers in certain countries but not in others. It was also suggested that applying worldwide general protein biomarkers for OSCC detection would be very difficult; thus, the need to conduct population-tailored proteomics studies should be emphasized ${ }^{24}$. 


\section{Biomarker expression}

Saliva as a diagnostic fluid has been shown to manifest altered expression of biomarkers not only in OSCC but in various oral and systemic diseases ${ }^{25-29}$. Historically, serum CYFRA 21-1 was originally investigated as a biomarker for nonsmall-cell lung carcinoma (NSCLC) and was then evaluated in other malignant and non-malignant diseases ${ }^{30-32}$. Several studies have reported the usefulness of serum CYFRA 21-1 as a biomarker in different conditions including breast cancer, gastric cancer, intrahepatic cholangiocarcinoma (ICC), colorectal cancer, cervical cancer, urinary bladder cancer, and malignant mesothelioma ${ }^{33-41}$. In the head and neck region, serum CYFRA 21-1 could also be a useful biomarker in nasopharyngeal carcinoma, hypopharyngeal carcinoma, oropharyngeal cancer, and OSCC ${ }^{14,15,41,42}$. The studies by Malhotra et al. ${ }^{14}$ and Rajkumar et al. ${ }^{15}$, which were both included in this review, evaluated the correlation between the serum and salivary CYFRA 21-1 in OSCC. Rajkumar et al. ${ }^{15}$ found that salivary CYFRA 21-1 levels were three-fold higher when compared to serum levels $(P<0.001)$ and increased in stage IV in both serum and saliva. Malhotra et al. ${ }^{14}$, on the other hand, found a significant correlation between serum and salivary CYFRA 21-1 $(P=0.002)$ and showed that both salivary and serum CYFRA 21-1 levels were significantly elevated in grade II OSCC compared to grade I. At the same time, other previous studies have shown various results regarding the differences in CYFRA 21-1 levels according to the clinical stage $e^{43-45}$, while other studies have claimed no correlation ${ }^{46,47}$.

Similarly, altered MMP-9 expression in tissues and biofluids has also been evaluated in an extensive number of studies that have explored its role in different diseases and malignancies. Studies have shown elevated tissue MMP-9 levels in many 
types of malignancy such as squamous cell carcinoma of the uterine cervix, ovarian cancer, endometrial cancer, breast cancer, adenocarcinoma of the lung, NSCLC, papillary thyroid cancer, gastric cancer, colorectal cancer, and salivary gland cancer ${ }^{48-}$ ${ }^{57}$. Furthermore, serum MMP-9 has also been shown to be elevated in breast cancer, pancreatic ductal adenocarcinoma, and NSCLC ${ }^{58-61}$. Moreover, MMP-9 can be found in urine, plasma, and cerebrospinal fluid in various types of malignancy, and has been found to be elevated in the gingival crevicular fluid (GCF) of patients with rheumatoid arthritis as well ${ }^{62,63}$. In the head and neck region, MMP-9 overexpression has been shown not only in saliva but also in plasma, tissue, and GCF in oral PMDs such as oral lichen planus, leukoplakia, oral submucous fibrosis, and chronic periodontitis $^{63-67}$.

Since CYFRA 21-1 and MMP-9 can be expressed in various cellular stages and diseases such as inflammatory diseases and malignancies, it is important to explore their effectiveness as diagnostic biomarkers in each condition and to correlate their levels in different biofluids. Due to the nature of the existence of these biomarkers in various conditions, it is extremely challenging to consider them specific biomarkers for oral cancer. Therefore, the ability of these biomarkers to distinguish oral cancer from other co-morbidities is the keystone for the sake of clinical usefulness and future applications and development. One of the ideas that could help in reaching this goal is combining multiple biomarkers, as demonstrated in several studies; however, further studies are needed to investigate the effectiveness of multiple marker combinations ${ }^{24,68-70}$.

In conclusion, salivary biomarkers in general may have great potential in the early detection of OSCC and other diseases as well. However, due to the presence of biases and other limitations in the studies reviewed, there is no conclusive evidence of 
the value of singular salivary CYFRA 21-1 or MMP-9 analyses as screening tools for OSCC at the present time. Therefore, further standardized diagnostic test accuracy studies that minimize potential sources of bias through rigorous design, conduct, and reporting are needed. Reporting guidelines for primary diagnostic studies should be followed strictly ${ }^{71}$, and studies should address all potential sources of bias and applicability concerns as indicated in the QUADAS-2 tool ${ }^{12}$. Future research should focus on the accuracy of the current potential salivary biomarkers in the detection of OSCC with clear and robust methodology. Futures studies in oral cancer could be informed by studies of the diagnostic accuracy of combined salivary biomarker panels in other diseases, which could have similar altered expression of singular biomarkers.

\section{Funding}

No funding.

\section{Competing interests}

There are no conflicts of interest.

\section{Ethical approval}

Ethical approval was not needed.

\section{Patient consent}

Patient consent was not needed. 


\section{References}

1. British Dental Association. Opportunistic oral cancer screening: a management strategy for dental practice. London: British Dental Association, 2000. https://bda.org/dcps/policyandcampaigns/science-health/science-healthcampaigns/Documents/mouth_cancer.pdf [Accessibility verified [Au?5]] [Au?6] 2. Macey R, Walsh T, Brocklehurst P, Kerr AR, Liu JLY, Lingen MW, Ogden GR, Warnakulasuriya S, Scully C. Diagnostic tests for oral cancer and potentially malignant disorders in patients presenting with clinically evident lesions. Cochrane Database Syst Rev 2015: (5): CD010276.

3. Lee JM, Garon E, Wong DT. Salivary diagnostics. Orthod Craniofac Res 2009: 12: 206-211.

4. Yoshizawa JM, Schafer CA, Schafer JJ, Farrell JJ, Paster BJ, Wong DTW. Salivary biomarkers: toward future clinical and diagnostic utilities. Clin Microbiol Rev 2013: 26: 781-791.

5. Stuani VT, Rubira CMF, Sant'Ana ACP, Santos PSS. Salivary biomarkers as tools for oral squamous cell carcinoma diagnosis: a systematic review. Head Neck 2017: 39: 797-811.

6. Gualtero DF, Suarez Castillo A. Biomarkers in saliva for the detection of oral squamous cell carcinoma and their potential use for early diagnosis: a systematic review. Acta Odontol Scand 2016: 74: 170-177.

7. Rutjes AWS, Reitsma JB, Vandenbroucke JP, Glas AS, Bossuyt PMM. Casecontrol and two-gate designs in diagnostic accuracy studies. Clin Chem 2005: 51: $1335-1341$. 
8. Reitsma JB, Rutjes AWS, Whiting P, Vlassov VV, Leeflang MMG, Deeks JJ. Chapter 9: Assessing methodological quality. In: Deeks JJ, Bossuyt PM, Gatsonis C, eds.: Cochrane handbook for systematic reviews of diagnostic test accuracy version 1.0.0. The Cochrane Collaboration, 2009.

https://methods.cochrane.org/sites/methods.cochrane.org.sdt/files/public/uploads/ch09 _Oct09.pdf [Accessibility verified [Au?5]]

9. Yeung CA. Referrals to dentists by GPs could delay diagnosis of oral cancer. BMJ 2017: 356: i6784.

10. Moher D, Liberati A, Tetzlaff J, Altman DG; PRISMA Group. Preferred reporting items for systematic reviews and meta-analyses: the PRISMA statement. PLoS Med 2009: 6: e1000097.

11. Cochrane Collaboration. RevMan 5.3 user guide 2018. http:/community.cochrane.org/sites/default/files/uploads/inlinefiles/RevMan_5.3_User_Guide.pdf [Accessibility verified [Au?5]]

12. Whiting PF, Rutjes AWS, Westwood ME, Mallett S, Deeks JJ, Reitsma JB, et al. [Au?7] QUADAS-2: a revised tool for the quality assessment of diagnostic accuracy studies. Ann Intern Med 2011: 155: 529-536.

13. Awasthi N. Role of salivary biomarkers in early detection of oral squamous cell carcinoma. Indian J Pathol Microbiol 2017: 60: 464-468.

14. Malhotra R, Urs AB, Chakravarti A, Kumar S, Gupta VK, Mahajan B. Correlation of Cyfra 21-1 levels in saliva and serum with CK19 mRNA expression in oral squamous cell carcinoma. Tumour Biol 2016: 37: 9263-9271.

15. Rajkumar K, Ramya R, Nandhini G, Rajashree P, Ramesh Kumar A, Nirmala Anandan S. Salivary and serum level of CYFRA 21-1 in oral precancer and oral squamous cell carcinoma. Oral Dis 2015: 21: 90-96. 
16. Ghallab NA, Shaker OG. Serum and salivary levels of chemerin and MMP-9 in oral squamous cell carcinoma and oral premalignant lesions. Clin Oral Investig 2017: 21: 937-947.

17. Peisker A, Raschke GF, Fahmy MD, Guentsch A, Roshanghias K, Hennings J, Schultze-Mosgau S. Salivary MMP-9 in the detection of oral squamous cell carcinoma. Med Oral Patol Oral Cir Bucal 2017: 22: e270-e275.

18. Yu JS, Chen YT, Chiang WF, Hsiao YC, Chu LJ, See LC, Wu CS, Tu HT, Chen HW, Chen CC, Liao WC, Chang YT, Wu CC, Lin CY, Liu SY, Chiou ST, Chia SL, Chang KP, Chien CY, Chang SW, Chang CJ, Young JD, Pao CC, Chang YS, Hartwell LH. Saliva protein biomarkers to detect oral squamous cell carcinoma in a high-risk population in Taiwan. Proc Natl Acad Sci 2016: 113: 11549-11554.

19. Cohen JF, Korevaar DA, Altman DG, Bruns DE, Gatsonis CA, Hooft L, et al. [Au?7] STARD 2015 guidelines for reporting diagnostic accuracy studies:

explanation and elaboration. BMJ Open 2016: 6: e012799.

20. Cheng YSL, Rees T, Wright J. A review of research on salivary biomarkers for oral cancer detection. Clin Transl Med 2014: 3: 3.

21. Sankaranarayanan R, Ramadas K, Amarasinghe H, Subramanian S, Johnson N. Oral cancer: prevention, early detection, and treatment. In: Gelband H, Jha P, Sankaranarayanan R, Horton S, eds.: Cancer: disease control priorities. Third edition (Volume 3). Washington DC: [Au?8], 2015.

22. Gupta PC, Mehta FS, Daftary DK, Pindborg JJ, Bhonsle RB, Jalnawalla PN, et al. [Au?7] Incidence rates of oral cancer and natural history of oral precancerous lesions in a 10-year follow-up study of Indian villagers. Community Dent Oral Epidemiol 1980: 8: 283-333. 
23. Pervez S, Abro B. Oral cancer and chewing habits. In: Moustafa AEA, ed.: Development of oral cancer. Switzerland: Springer International Publishing, 2017: $115-132$.

24. Csősz É, Lábiscsák P, Kalló G, Márkus B, Emri M, Szabó A, et al. [Au?7] Proteomics investigation of OSCC-specific salivary biomarkers in a Hungarian population highlights the importance of identification of population-tailored biomarkers. PLoS One 2017: 12: e0177282.

25. Buczko P, Zalewska A, Szarmach I. Saliva and oxidative stress in oral cavity and in some systemic disorders. J Physiol Pharmacol 2015: 66: 3-9.

26. Zhang L, Farrell JJ, Zhou H, Elashoff D, Akin D, Park NH, et al. [Au?7] Salivary transcriptomic biomarkers for detection of resectable pancreatic cancer. Gastroenterology 2010: 138: 949-57.e577.

27. Streckfus CF, Mayorga-Wark O, Arreola D, Edwards C, Bigler L, Dubinsky WP. Breast cancer related proteins are present in saliva and are modulated secondary to ductal carcinoma in situ of the breast. Cancer Invest 2008: 26: 159-167.

28. Li X, Yang T, Lin J. Spectral analysis of human saliva for detection of lung cancer using surface-enhanced Raman spectroscopy. J Biomed Opt 2012: 17: 037003. 29. Lee YH, Kim JH, Zhou H, Kim BW, Wong DT. Salivary transcriptomic biomarkers for detection of ovarian cancer: for serous papillary adenocarcinoma. $\mathrm{J}$ Mol Med (Berl) 2012: 90: 427-434.

30. H B, D B, B O, D J, A D [Au?9]. Technical evaluation of a new automated tumor marker assay: the Enzymun-Test CYFRA 21-1. In: Klapdor R, ed.: Tumor associated antigens, oncogenes, receptors, cytokines in tumor diagnosis and therapy at the beginning of the 90s. Munich, Germany: Zuckschwerdt, 1992: 137-138. 
31. Stieber P, Hasholzner U, Bodenmuller H, Nagel D, Sunder-Plassmann L, Dienemann H, et al. [Au?7] CYFRA 21-1. A new marker in lung cancer. Cancer 1993: 72: 707-713.

32. Molina R, Agusti C, Filella X, Jo J, Joseph J, Giménez N, et al. [Au?7] Study of a new tumor marker, CYFRA21-1, in malignant and nonmalignant diseases. Tumour Biol 1994: 15: 318-325.

33. Nakata B, Takashima T, Ogawa Y, Ishikawa T, Hirakawa K. Serum CYFRA 21-1 (cytokeratin-19 fragments) is a useful tumour marker for detecting disease relapse and assessing treatment efficacy in breast cancer. Br J Cancer 2004: 91: 873878.

34. Rodríguez CA, Cruz JJ, Martín T, Gómez A, Olaverri A, Hernández M. Serum CYFRA 21-1 is one of the most reliable tumor markers for breast carcinoma. Cancer 2002: 95: 670-671.

35. Choi JS, Han KH, Kim EK, Moon HJ, Yoon JH, Kim MJ. Fine-needle aspirate CYFRA 21-1, an innovative new marker for diagnosis of axillary lymph node metastasis in breast cancer patients. Medicine (Baltimore) 2015: 94: e811.

36. Nakata B, Chung YS, Kato Y, Ogawa M, Ogawa Y, Inui A, et al. [Au?7] Clinical significance of serum CYFRA 21-1 in gastric cancer. Br J Cancer 1996: 73: 1529-1532.

37. Uenishi T, Kubo S, Hirohashi K, Tanaka H, Shuto T, Yamamoto T, et al. [Au?7] Cytokeratin-19 fragments in serum (CYFRA 21-1) as a marker in primary liver cancer. Br J Cancer 2003: 88: 1894-1899.

38. Miyashita T, Nishimura G, Michiwa Y, Sato T, Tsugawa K, Fushida S, et al. [Au?7] [Clinical usefulness of serum CYFRA21-1 in colorectal cancer]. Gan To Kagaku Ryoho 1996: 23: 1693-1696. 
39. Suzuki Y, Nakano T, Ohno T, Abe A, Morita S, Tsujii H. Serum CYFRA 21-1 in cervical cancer patients treated with radiation therapy. J Cancer Res Clin Oncol 2000: 126: 332-336.

40. Stieber P, Schmeller N, Schambeck C, Hofmann K, Reiter W, Hasholzner U, et al. [Au?7] Clinical relevance of CYFRA 21-1, TPA-IRMA and TPA-LIA-mat in urinary bladder cancer. Anticancer Res 1996: 16(6B): 3793-3798.

41. Bonfrer JM, Schouwink JH, Korse CM, Baas P. Cyfra 21-1 and TPA as markers in malignant mesothelioma. Anticancer Res 1997: 17(4B): 2971-2973. 42. Sawant SS, Zingde SM, Vaidya MM. Cytokeratin fragments in the serum: their utility for the management of oral cancer. Oral Oncol 2008: 44: 722-732. 43. Ceruse P, Rabilloud M, Charrie A, Dubreuil C, Disant F. Study of Cyfra 21-1, a tumor marker, in head and neck squamous cell carcinoma. Ann Otol Rhinol Laryngol 2005: 114: 768-776.

44. Deng YF, Chen P, Lin YZ, Le JZ, Wu XL, Yu MQ, et al. [Au?7] Analytical and clinical evaluation of CYFRA 21-1 by electrochemiluminescent immunoassay in head and neck squamous cell carcinoma. J Laryngol Otol 2003: 117: 190-194.

45. Doweck I, Barak M, Greenberg E, Uri N, Kellner J, Lurie M, et al. [Au?7] Cyfra 21-1. A new potential tumor marker for squamous cell carcinoma of head and neck. Arch Otolaryngol Head Neck Surg 1995: 121: 177-181.

46. Zhong LP, Zhang CP, Zheng JW, Li J, Chen WT, Zhang ZY. Increased Cyfra 21-1 concentration in saliva from primary oral squamous cell carcinoma patients. Arch Oral Biol 2007: 52: 1079-1087.

47. Bongers V, Braakhuis BJM, Snow GB. Circulating fragments of cytokeratin 19 in patients with head and neck squamous cell carcinoma. Clin Otolaryngol Allied Sci 1995: 20: 479-482. 
48. Yu W, Liu J, Xiong X, Ai Y, Wang H. Expression of MMP9 and CD147 in invasive squamous cell carcinoma of the uterine cervix and their implication. Pathol Res Pract 2009: 205: 709-715.

49. Davidson B, Goldberg I, Berner A, Kristensen GB, Reich R. EMMPRIN (extracellular matrix metalloproteinase inducer) is a novel marker of poor outcome in serous ovarian carcinoma. Clin Exp Metastasis 2003: 20: 161-169.

50. Aglund K, Rauvala M, Puistola U, Angstrom T, Turpeenniemi-Hujanen T, Zackrisson B, et al. [Au?7] Gelatinases A and B (MMP-2 and MMP-9) in endometrial cancer-MMP-9 correlates to the grade and the stage. Gynecol Oncol 2004: 94: 699704.

51. McGowan PM, Duffy MJ. Matrix metalloproteinase expression and outcome in patients with breast cancer: analysis of a published database. Ann Oncol 2008: 19: $1566-1572$.

52. Kodate M, Kasai T, Hashimoto H, Yasumoto K, Iwata Y, Manabe H. Expression of matrix metalloproteinase (gelatinase) in T1 adenocarcinoma of the lung. Pathol Int 1997: 47: 461-469.

53. Cox G, Jones JL, O’Byrne KJ. Matrix metalloproteinase 9 and the epidermal growth factor signal pathway in operable non-small cell lung cancer. Clin Cancer Res 2000: 6: 2349-2355.

54. Maeta H, Ohgi S, Terada T. Protein expression of matrix metalloproteinases 2 and 9 and tissue inhibitors of metalloproteinase 1 and 2 in papillary thyroid carcinomas. Virchows Arch 2001: 438: 121-128.

55. Sier CF, Kubben FJ, Ganesh S, Heerding MM, Griffioen G, Hanemaaijer R, et al. [Au?7] Tissue levels of matrix metalloproteinases MMP-2 and MMP-9 are related 
to the overall survival of patients with gastric carcinoma. Br J Cancer 1996: 74: 413417.

56. Zeng ZS, Huang Y, Cohen AM, Guillem JG. Prediction of colorectal cancer relapse and survival via tissue RNA levels of matrix metalloproteinase-9. J Clin Oncol 1996: 14: 3133-3140.

57. Luukkaa H, Klemi P, Hirsimaki P, Vahlberg T, Kivisaari A, Kahari VM, et al. [Au?7] Matrix metalloproteinase (MMP)-7 in salivary gland cancer. Acta Oncol 2010: 49: 85-90.

58. Wu ZS, Wu Q, Yang JH, Wang HQ, Ding XD, Yang F, et al. [Au?7] Prognostic significance of MMP-9 and TIMP-1 serum and tissue expression in breast cancer. Int J Cancer 2008: 122: 2050-2056.

59. La Rocca G, Pucci-Minafra I, Marrazzo A, Taormina P, Minafra S. Zymographic detection and clinical correlations of MMP-2 and MMP-9 in breast cancer sera. Br J Cancer 2004: 90: 1414-1421.

60. Tian M, Cui YZ, Song GH, Zong MJ, Zhou XY, Chen Y, et al. [Au?7] Proteomic analysis identifies MMP-9, DJ-1 and A1BG as overexpressed proteins in pancreatic juice from pancreatic ductal adenocarcinoma patients. BMC Cancer 2008: 8: 241.

61. Jumper C, Cobos E, Lox C. Determination of the serum matrix metalloproteinase-9 (MMP-9) and tissue inhibitor of matrix metalloproteinase-1 (TIMP-1) in patients with either advanced small-cell lung cancer or non-small-cell lung cancer prior to treatment. Respir Med 2004: 98: 173-177.

62. Roy R, Yang J, Moses MA. Matrix metalloproteinases as novel biomarkers and potential therapeutic targets in human cancer. J Clin Oncol 2009: 27: 5287-5297. 
63. Silosi I, Cojocaru M, Foia L, Boldeanu MV, Petrescu F, Surlin P, et al. [Au?7] Significance of circulating and crevicular matrix metalloproteinase-9 in rheumatoid arthritis-chronic periodontitis association. J Immunol Res 2015: 2015: 218060.

64. Singh RD, Nilayangode H, Patel JB, Shah FD, Shukla SN, Shah PM, et al. [Au?7] Combined evaluation of matrix metalloproteinases and their inhibitors has better clinical utility in oral cancer. Int J Biol Markers 2011: 26: 27-36.

65. P OC [Au?10], Rhys-Evans PH, Eccles SA. Expression of matrix metalloproteinases and their inhibitors correlates with invasion and metastasis in squamous cell carcinoma of the head and neck. Arch Otolaryngol Head Neck Surg 2001: 127: 813-820.

66. Venugopal A, Uma Maheswari TN. Expression of matrix metalloproteinase-9 in oral potentially malignant disorders: a systematic review. J Oral Maxillofac Pathol 2016: 20: 474-479.

67. Makela M, Salo T, Uitto VJ, Larjava H. Matrix metalloproteinases (MMP-2 and MMP-9) of the oral cavity: cellular origin and relationship to periodontal status. J Dent Res 1994: 73: 1397-1406.

68. Heawchaiyaphum C, Pientong C, Phusingha P, Vatanasapt P, Promthet S, Daduang J, et al. [Au?7] Peroxiredoxin-2 and zinc-alpha-2-glycoprotein as potentially combined novel salivary biomarkers for early detection of oral squamous cell carcinoma using proteomic approaches. J Proteomics 2018: 173: 52-61.

69. Ishikawa S, Sugimoto M, Kitabatake K, Sugano A, Nakamura M, Kaneko M, et al. [Au?7] Identification of salivary metabolomic biomarkers for oral cancer screening. Sci Rep 2016: 6: 31520. 
70. Wei J, Xie G, Zhou Z, Shi P, Qiu Y, Zheng X, et al. [Au?7] Salivary metabolite signatures of oral cancer and leukoplakia. Int J Cancer 2011: 129: 2207 2217.

71. Bossuyt PM, Reitsma JB, Bruns DE, Gatsonis CA, Glasziou PP, Irwig L, et al. [Au?7] STARD 2015: an updated list of essential items for reporting diagnostic accuracy studies. BMJ 2015: 351: h5527. 


\section{Figure captions}

Fig. 1. PRISMA flow diagram of the search strategy. [Au?11]

Fig. 2. Summary of the risk of bias and applicability concerns for each included study on CYFRA 21-1. [Au?12]

Fig. 3. Summary of the risk of bias and applicability concerns for each included study on MMP-9.

Fig. 4. Forest plot showing the sensitivity and specificity of CYFRA 21-1 studies.

\section{[Au?12]}

Fig. 5. Forest plot showing the sensitivity and specificity of MMP-9 studies. 


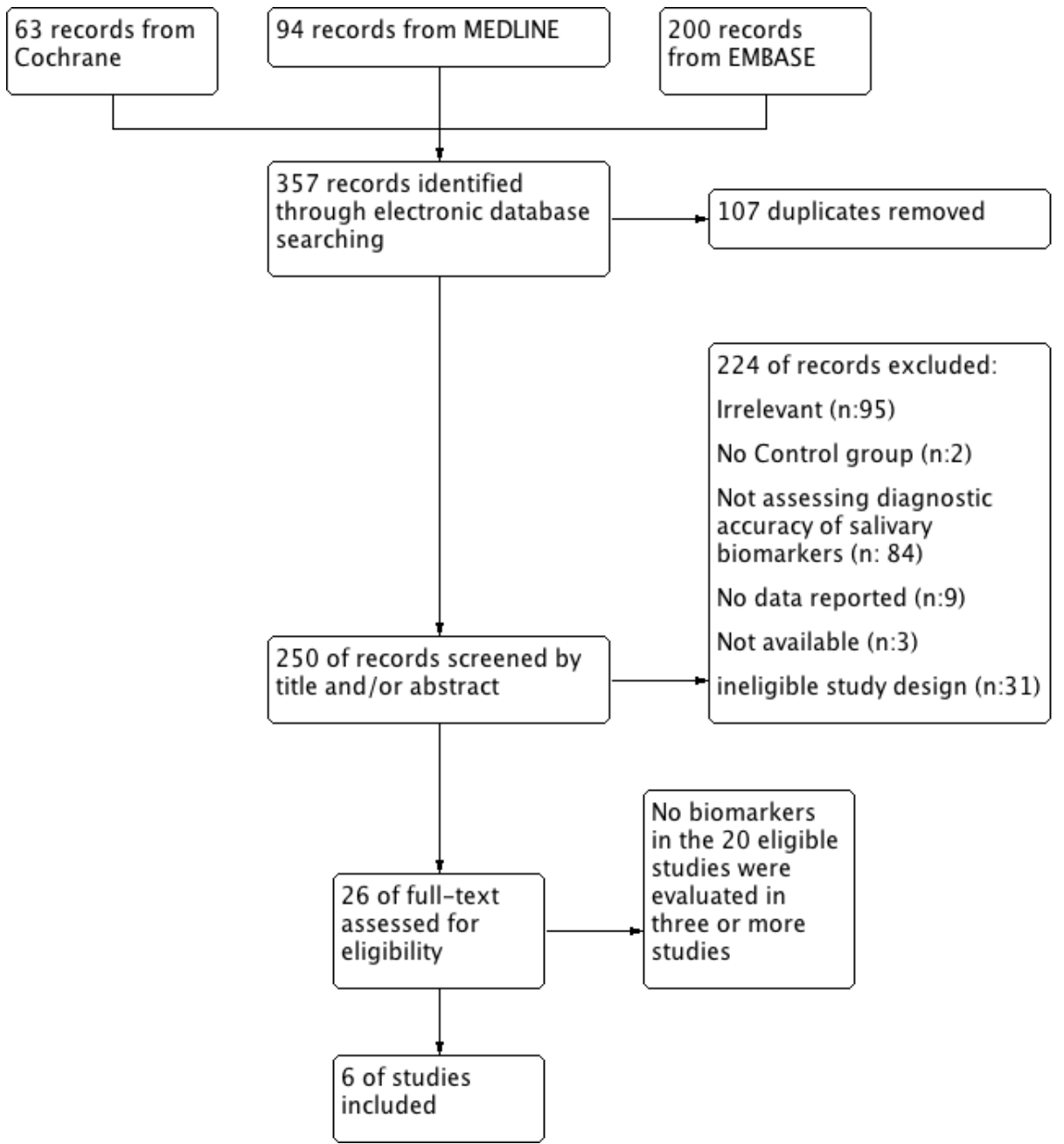

Figure 1 


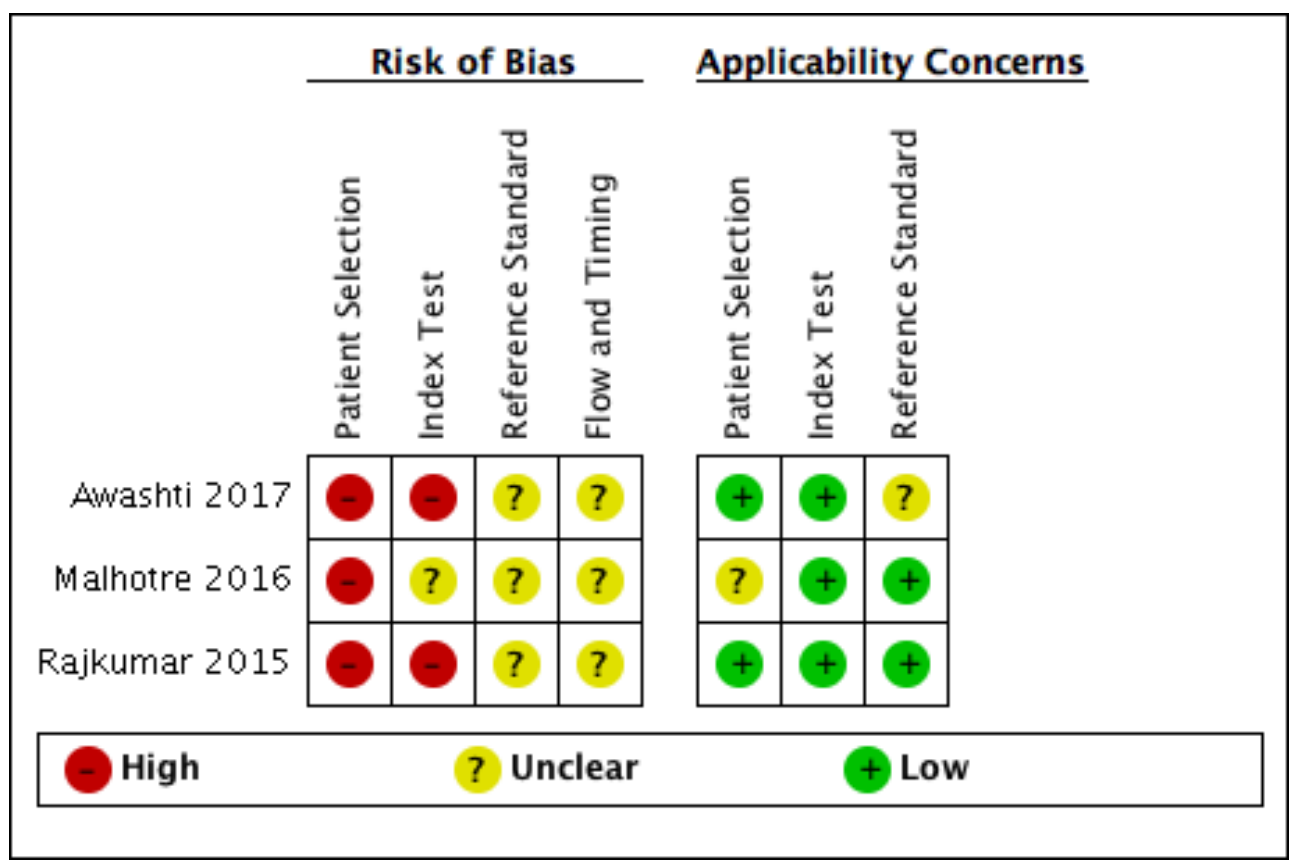

Figure 2 


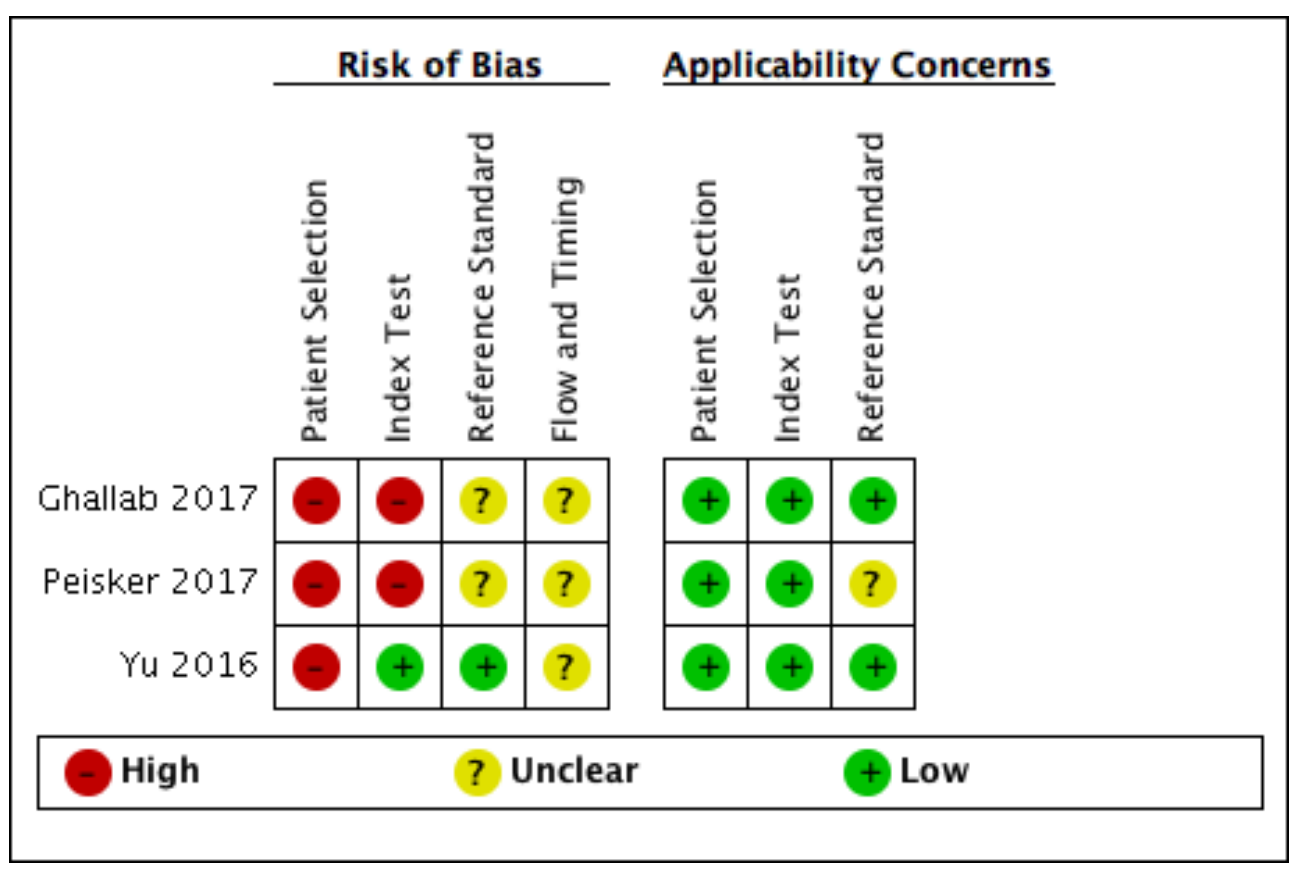

Figure 3 
Figure 4 
Study

Ghallab 2017

Peisker 2017

Yu 2016

$\begin{array}{rrrrr}15 & 0 & 0 & 15 & 1.00[0.78,1.00] \\ 30 & 22 & 0 & 8 & 1.00[0.88,1.00]\end{array}$

$\begin{array}{lllll}99 & 79 & 32 & 120 & 0.76\end{array}[0.67,0.83]$

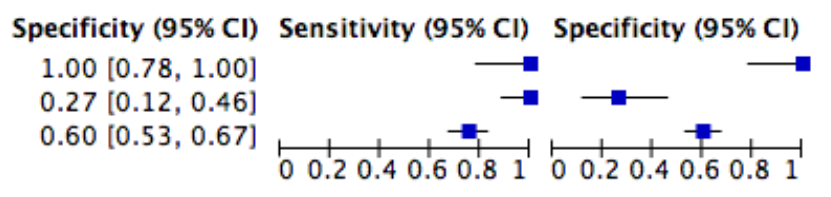

Figure 5 
Table 1. QUADAS-2 indicators adapted for the current systematic review.

\begin{tabular}{|c|c|c|c|c|}
\hline Domain & Patient selection & Index test & Reference standard & Flow and timing \\
\hline Signalling questions & Was a consecutive or random & Were the index test results & Is the reference standard likely to & Was there an appropriate interval \\
\hline (Yes, No, or & sample of patients enrolled? & interpreted without knowledge of & correctly classify the target & between the index test and \\
\hline \multirow[t]{13}{*}{ Unclear) } & & the results of the reference & condition? & reference standard? \\
\hline & & standard? & & \\
\hline & Yes: if consecutive patients or a & Yes: if interpreters of the index test & Yes: if the biopsy was & Yes: if the delay between the index \\
\hline & random sample of individuals were & results clearly did not know the & independently confirmed by at least & test and reference standard was \\
\hline & recruited & results of biopsy/histopathology & two qualified pathologists & considered acceptable for the \\
\hline & No: if non-consecutive patients or a & No: if interpreters of the index test & No: if the biopsy was not & majority of participants \\
\hline & non-random sample of individuals & results clearly knew the results of & independently confirmed by at least & No: if the delay between the index \\
\hline & were recruited & biopsy/histopathology & two qualified pathologists, or there & test and reference standard was \\
\hline & Unclear: if patient selection was not & Unclear: if the study did not provide & was a lack of agreement between & considered unacceptable for the \\
\hline & clearly described & any information on whether & pathologists & majority of participants \\
\hline & & interpreters of the index tests were & Unclear: if the study did not state & Unclear: if the delay between the \\
\hline & & blinded to biopsy/histopathology & who confirmed the biopsy & index test and reference standard \\
\hline & & & & was not explicitly stated \\
\hline
\end{tabular}




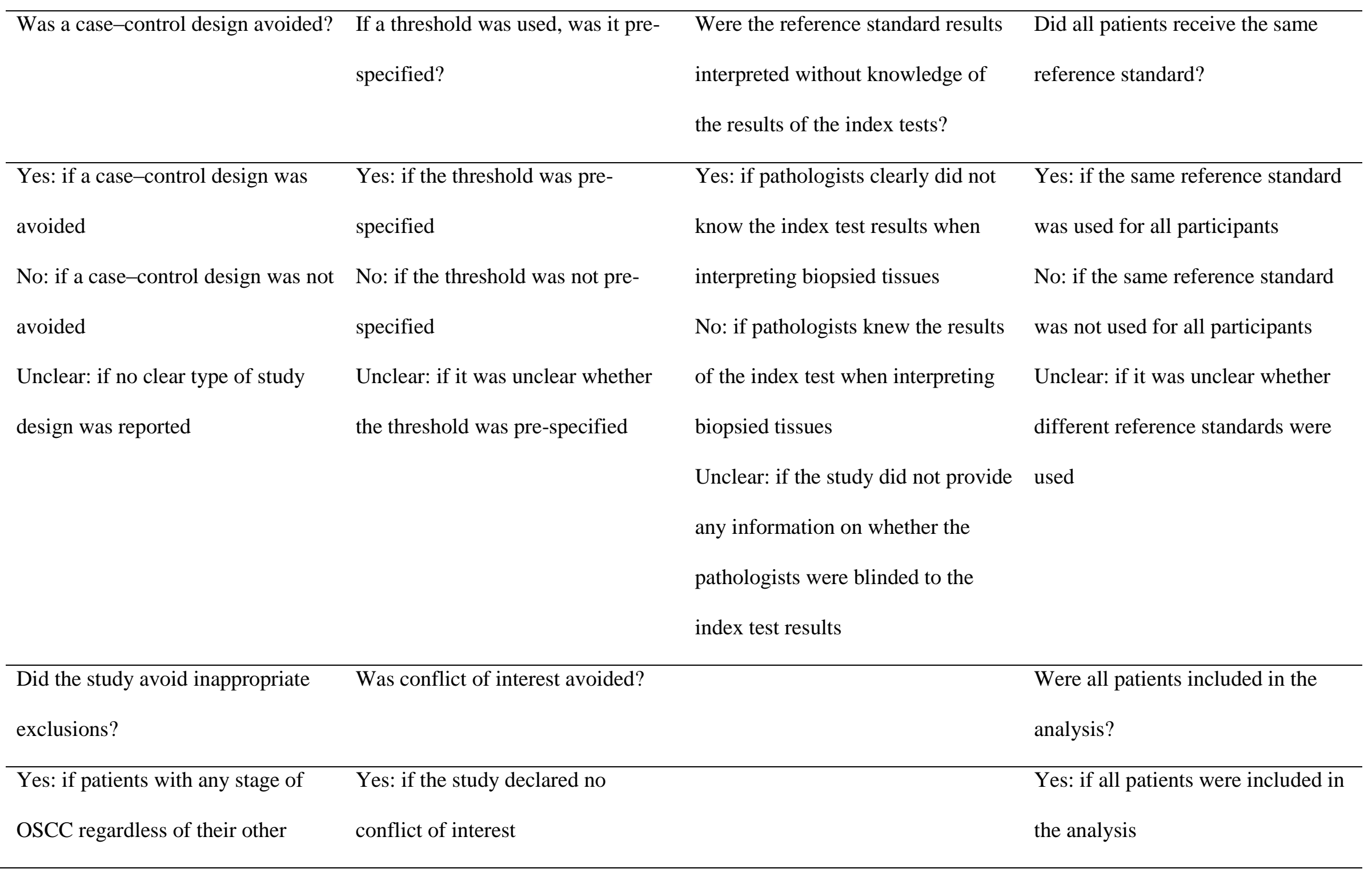


systemic diseases (with no prior

chemotherapy or radiotherapy)

were recruited

No: if patients with common

diseases/drugs seen in practice were

excluded

Unclear: if no clear inclusion and

exclusion criteria were reported
No: if the study declared a conflict

of interest

Unclear: if there was no

information on conflict of interest
No: if only some patients were

included in the analysis

Unclear: if it was unclear whether

all patients were included in the

analysis

\begin{tabular}{|c|c|c|c|c|}
\hline \multirow[t]{2}{*}{ Overall risk of bias } & $\begin{array}{l}\text { Could the selection of patients have } \\
\text { introduced bias? }\end{array}$ & $\begin{array}{l}\text { Could the conduct or interpretation } \\
\text { of the index test have introduced }\end{array}$ & $\begin{array}{l}\text { Could the reference standard, its } \\
\text { conduct, or its interpretation have }\end{array}$ & $\begin{array}{l}\text { Could the patient flow have } \\
\text { introduced bias? }\end{array}$ \\
\hline & & bias? & introduced bias? & \\
\hline
\end{tabular}

High: if answered 'No' to any question

Low: if answered 'Yes' to all questions

Unclear: if answered 'Unclear' to all questions or accompanied by any 'Yes'

\begin{tabular}{|c|c|c|c|}
\hline Concerns regarding & Are there concerns that the included & Are there concerns that the index & Are there concerns that the target \\
\hline applicability: High, & patients do not match the review & test, its conduct, or interpretation & condition, as defined by the \\
\hline Low, or Unclear & question? & differ from the review question? & \\
\hline
\end{tabular}


reference standard, does not match

the review question?

OSCC, oral squamous cell carcinoma. 
Table 2. Summary of the data extracted from the included studies. [Au?13]

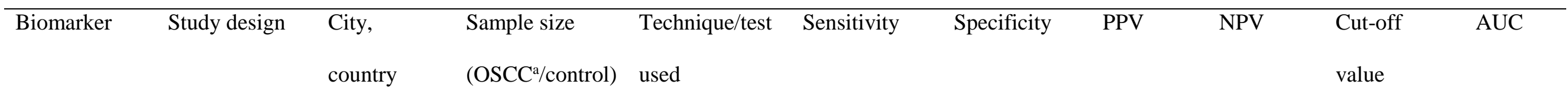

CYFRA 21-1 Awasthi N. Role of salivary biomarkers in early detection of oral squamous cell carcinoma. Indian J Pathol Microbiol 2017: 60: 464-468.

Years conducted: 2010 to $2011^{13}$

\begin{tabular}{|c|c|c|c|c|c|c|c|c|}
\hline Two-gate $^{b}$ & Lucknow, & $55(30 / 25)$ & ELISA & $90 \%$ & $97 \%$ & $96.4 \%$ & $91.7 \%$ & $8.7 \mathrm{ng} / \mathrm{ml}$ \\
\hline (Case-control) & India & & & & $(96 \%)^{\mathrm{C}}$ & & (88.9\%) & \\
\hline
\end{tabular}

Malhotra R, Urs A, Chakravarti A, Kumar S, Gupta V, Mahajan B. Correlation of Cyfra 21-1 levels in saliva and serum with CK19 mRNA expression in oral squamous cell carcinoma. Tumour Biol 2016: 37: 9263-9271.

Year conducted: Unknown ${ }^{14}$

\begin{tabular}{|c|c|c|c|c|c|c|c|c|}
\hline Two-gate $^{b}$ & New Delhi, & $100(50 / 50)$ & ECLIA & $93.8 \%$ & $84.3 \%$ & $85.5 \%{ }^{c}$ & $93.3 \%{ }^{c}$ & $8.5 \mathrm{ng} / \mathrm{ml}$ \\
\hline (Case-control) & India & & & $(94 \%)^{c}$ & $(84 \%)^{\mathrm{c}}$ & & & \\
\hline
\end{tabular}

Rajkumar K, Ramya R, Nandhini G, Rajashree P, Ramesh Kumar A, Nirmala Anandan S. Salivary and serum level of CYFRA 21-1 in oral precancer and oral squamous cell carcinoma. Oral Dis 2015: 21: 90-96.

Years conducted: 2009 to $2012^{15}$

\begin{tabular}{|c|c|c|c|c|c|c|c|c|c|}
\hline Two-gate ${ }^{b}$ & Chennai, & $200(100 / 100)$ & ELISA & $83.6 \%$ & $95 \%$ & $94.4 \%{ }^{\mathrm{c}}$ & $85.6 \%{ }^{\mathrm{c}}$ & $>7.91 \mathrm{ng} / \mathrm{ml}$ & 0.895 \\
\hline (Case-control) & India & & & $(84 \%)^{\mathrm{C}}$ & & & & & \\
\hline
\end{tabular}


Investig 2017: 21: 937-947.

Year conducted: $2014^{16}$

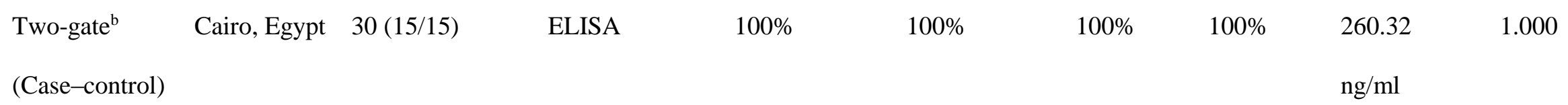

Peisker A, Raschke G, Fahmy M, Guentsch A, Roshanghias K, Hennings J, Schultze-Mosgau S. Salivary MMP-9 in the detection of oral squamous cell carcinoma. Med Oral Patol Oral Cir Bucal 2017: 22: e270-e275.

Year conducted: Unknown ${ }^{17}$

\begin{tabular}{|c|c|c|c|c|c|c|c|c|}
\hline Two-gate ${ }^{b}$ & Jena, & $60(30 / 30)$ & ELISA & $100 \%$ & $26.7 \%$ & $57.7 \%^{\mathrm{c}}$ & $100 \%{ }^{c}$ & $>0.104$ \\
\hline (Case-control) & Germ & & & & $(27 \%)^{\mathrm{C}}$ & & & (Unit NR \\
\hline
\end{tabular}

Yu J, Chen Y, Chiang W, Hsiao Y, Chu L, See L, et al. Saliva protein biomarkers to detect oral squamous cell carcinoma in a high-risk population in

Taiwan. Proc Natl Acad Sci 2016: 113: 11549-11554.

Years conducted: 2008 to $2013^{18}$

\begin{tabular}{|c|c|c|c|c|c|c|c|c|}
\hline Two-gate $^{\mathrm{b}}$ & Taiwan & $330(131 / 199)$ & Multiplex LC- & $75.6 \%$ & $60.3 \%$ & $55.6 \%{ }^{c}$ & $79 \%{ }^{\mathrm{c}}$ & $\mathrm{NR}$ \\
\hline (Case-control) & & & MRM-MS & $(76 \%)^{c}$ & & & & \\
\hline
\end{tabular}

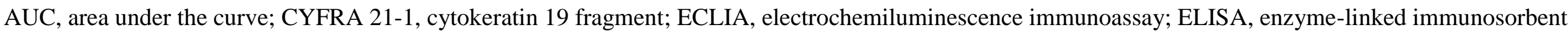

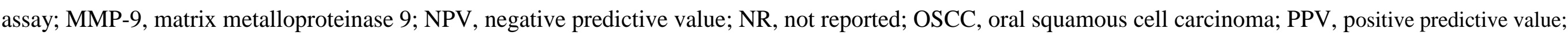


${ }^{\mathrm{a}}$ According to histopathological examination.

${ }^{\mathrm{b}}$ According to Rutjes et al. ${ }^{7}$ [Au?14].

${ }^{c}$ Values obtained using the RevMan calculator when not reported, or when our calculation differed from the reported value. 
Table 3. Summary of the findings and quality assessment.

What is the diagnostic accuracy of the current salivary biomarkers used in the detection of OSCC?

Patient population Adults (aged $\geq 16$ years) suspected of having OSCC with no prior treatment such as chemotherapy or radiotherapy

Index test

Salivary analysis for CYFRA 21-1 and MMP-9 singular biomarkers only (not combined)

Reference standard

Biopsy with histopathological examination

Target condition

Oral squamous cell carcinoma (OSCC)

Included studies

$N=6$ two-gate (case-control) studies

Quality assessment

None of the included studies could be classified as being at low risk of bias in all of the four domains, which are patient selection, index test, reference standards, and flow and timing. The overall quality of the included studies for both

CYFRA 21-1 and MMP-9 was poor and mainly limited by a poor patient selection process, unclear blinding implementation, and small sample sizes.

\begin{tabular}{|c|c|c|c|c|}
\hline Biomarker & $\begin{array}{l}\text { Sensitivity }(95 \% \mathrm{CI}) \\
\text { Range }\end{array}$ & $\begin{array}{l}\text { Specificity }(95 \% \mathrm{CI}) \\
\text { Range }\end{array}$ & $\begin{array}{l}\text { Number of total } \\
\text { participants/OSCC cases/ } \\
\text { non-OSCC cases }\end{array}$ & Quality \\
\hline CYFRA 21-1 & $\begin{array}{l}0.84(0.75-0.91) \text { to } 0.94 \\
(0.83-0.99)\end{array}$ & $\begin{array}{l}0.84(0.71-0.93) \text { to } 0.96 \\
(0.80-1.00)\end{array}$ & $355 / 180 / 175$ & High risk of bias \\
\hline
\end{tabular}


